\title{
Mapping Invasive Phragmites australis Using Unoccupied Aircraft System Imagery, Canopy Height Models, and Synthetic Aperture Radar
}

\author{
Connor J. Anderson ${ }^{1, *}$, Daniel Heins ${ }^{1}$, Keith C. Pelletier ${ }^{1}$, Julia L. Bohnen ${ }^{2}$ and Joseph F. Knight ${ }^{1} \mathbb{D}$ \\ 1 Department of Forest Resources, University of Minnesota, 1530 Cleveland Ave. N, St. Paul, MN 55108, USA; \\ hein0041@umn.edu (D.H.); pelle155@umn.edu (K.C.P.); jknight@umn.edu (J.F.K.) \\ 2 Department of Fisheries, Wildlife, and Conservation Biology, University of Minnesota, 2003 Upper Buford \\ Circle, St. Paul, MN 55108, USA; bohne001@umn.edu \\ * Correspondence: and03010@umn.edu
}

check for updates

Citation: Anderson, C.J.; Heins, D. Pelletier, K.C.; Bohnen, J.L.; Knight, J.F. Mapping Invasive Phragmites australis Using Unoccupied Aircraft System Imagery, Canopy Height Models, and Synthetic Aperture Radar. Remote Sens. 2021, 13, 3303. https: / /doi.org/10.3390/ rs13163303

Academic Editors: Sandra Eckert and Urs Schaffner

Received: 30 June 2021

Accepted: 16 August 2021

Published: 20 August 2021

Publisher's Note: MDPI stays neutral with regard to jurisdictional claims in published maps and institutional affiliations.

Copyright: (c) 2021 by the authors. Licensee MDPI, Basel, Switzerland. This article is an open access article distributed under the terms and conditions of the Creative Commons Attribution (CC BY) license (https:// creativecommons.org/licenses/by/ $4.0 /)$.
Abstract: Invasive plant species are an increasing worldwide threat both ecologically and financially. Knowing the location of these invasive plant infestations is the first step in their control. Surveying for invasive Phragmites australis is particularly challenging due to limited accessibility in wetland environments. Unoccupied aircraft systems (UAS) are a popular choice for invasive species management due to their ability to survey challenging environments and their high spatial and temporal resolution. This study tested the utility of three-band (i.e., red, green, and blue; RGB) UAS imagery for mapping Phragmites in the St. Louis River Estuary in Minnesota, U.S.A. and Saginaw Bay in Michigan, U.S.A. Iterative object-based image analysis techniques were used to identify two classes, Phragmites and Not Phragmites. Additionally, the effectiveness of canopy height models (CHMs) created from two data types, UAS imagery and commercial satellite stereo retrievals, and the RADARSAT-2 horizontal-horizontal $(\mathrm{HH})$ polarization were tested for Phragmites identification. The highest overall classification accuracy of $90 \%$ was achieved when pairing the UAS imagery with a UAS-derived CHM. Producer's accuracy for the Phragmites class ranged from 3 to $76 \%$, and the user's accuracies were above 90\%. The Not Phragmites class had user's and producer's accuracies above $88 \%$. Inclusion of the RADARSAT- $2 \mathrm{HH}$ polarization caused a slight reduction in classification accuracy. Commercial satellite stereo retrievals increased commission errors due to decreased spatial resolution and vertical accuracy. The lowest classification accuracy was seen when using only the RGB UAS imagery. UAS are promising for Phragmites identification, but the imagery should be used in conjunction with a CHM.

Keywords: Phragmites australis; UAS; invasive species; object-based classification; OBIA

\section{Introduction}

Invasive species are a global problem with many negative impacts. An estimated USD 120 billion in damage is done annually by these species in the United States alone [1]. Phragmites australis (Cav.) Trin. Ex Steud. ssp. australis (hereafter Phragmites) is an invasive plant that has impaired wetlands, shorelines, and roadsides in the Great Lakes region and across much of the United States. It is a perennial grass that grows in a range of habitats from aquatic to terrestrial. Phragmites was originally introduced to the United States in the form of contaminated ballast material in the 18th or 19th centuries [2]. The regulatory status of Phragmites varies from state to state. In the state of Michigan, Phragmites is listed as a restricted plant [3], while in the state of Minnesota, its status was recently changed from a restricted noxious weed to a prohibited control species [4]. In Minnesota, restricted noxious weeds are plants whose importation, sale, and transportation are illegal. Prohibited control species share the same legalities with restricted noxious weeds for 
preventing spread; however, these species are legally required to be controlled by removing established populations.

Phragmites grows rapidly with the potential to reach up to $5 \mathrm{~m}$ tall. After becoming established, Phragmites quickly forms dense monotypic stands by using aerial seed dispersal and extensive networks of rhizomes. Phragmites can quickly become the dominant species in invaded areas due to fast growth rates [5], salinity tolerance [6], and by taking advantage of anthropogenic impacts to wetlands [7]. Examples of anthropogenic impacts include: removal of vegetation, soil removal or deposition, fragmentation, and pollutant runoff. Once established, this plant has the ability to alter hydrology [8], change nutrient cycles [9-11], and ultimately lead to a loss of biodiversity [12,13]. Minnesota also has populations of a native Phragmites genotype (Phragmites australis Trin. Ex. Steud. ssp. americanus Saltonst., P.M. Peterson and Soreng). In comparison, this native genotype does not exhibit the same growth and aggressiveness as the invasive Phragmites genotype. Native Phragmites has a smaller stature and generally does not form dense monotypic stands. Invasive Phragmites is spreading quickly in Minnesota and will likely see an expansion of its distribution [14].

Successful management of invasive species, such as Phragmites, depends heavily on knowing the location and extent of infestations. Physical mapping of invasive species, in the form of in situ monitoring, may be costly and requires large amounts of time and specialized equipment to access the locations of infestations. This, coupled with the interand-intra annual changes in distributions, leads to challenges for land managers attempting to control these pests. Current knowledge of Phragmites locations in Minnesota has been dependent on in situ monitoring. Individuals have reported Phragmites throughout the state through the Early Detection and Distribution Mapping System (EDDMapS) [15]. Although a remarkable resource, large-scale in situ mapping efforts cannot be completed quickly enough to track the changing distribution of Phragmites. Moreover, these survey methods may be hindered by a lack of access to private lands, physical inaccessibility of remote locations, and individuals unwilling to report locations.

Remote sensing has the potential to identify Phragmites over large areas without the requirement of extensive fieldwork. Satellites are collecting swaths of imagery daily, which can be acquired at minimal cost due to increased platform accessibility (Landsat or Sentinel) or through affiliations (university, federal, etc.). Occupied aircraft and unoccupied aircraft systems (UAS) are other often-used remote sensing technologies for conservation purposes [16-18]. Although occupied aircraft and UAS require upfront costs, such as equipment purchases or contractual services, and often lack the spectral resolution found in satellite-based platforms, they allow for spatial resolutions of less than $10 \mathrm{~cm}$ and flexible data acquisition. Each of these data have trade-offs between spatial, spectral, and temporal resolutions [19-21]. Research is needed to assess the different data and classification methods for remote sensing to be a viable tool for Phragmites detection.

Recent research has tested the use of remote sensing data for species identification. Hyperspectral sensors have been used to identify different vegetation types [22-24], including Phragmites [25]. Pengra et al. (2007) [25] used the EO-1 Hyperion hyperspectral sensor to identify Phragmites. It was noted that the moderate spatial resolution of the Hyperion sensor $(30 \mathrm{~m})$ hindered the identification of linear patches of Phragmites due to mixing of vegetation types within a pixel. Bourgeau-Chavez et al. (2013) [26] used a similar spatial resolution (20-30 m PALSAR and Landsat). They utilized backscatter intensities from multiple acquisitions of synthetic aperture radar (SAR) imagery to identify Phragmites with high producer's accuracies. SAR has been used extensively for vegetation identification and monitoring [27-32] because the backscattered energy is indicative of the geometric and dielectric properties of surface features [33]. Spaceborne sensors with higher spatial resolutions have also been studied for wetland and species mapping [34-40]. Laba et al. (2008) [39] reported consistently high accuracies for identifying Phragmites using QuickBird imagery and a maximum-likelihood classifier. They attributed the monotypic nature of Phragmites and the resulting consistent spectral values for accuracies of above $70 \%$. Another study used an object-based classification approach with WorldView-2 imagery to achieve 
classification accuracies of Phragmites above 90\% [40]. The high accuracies seen when using high-resolution satellite imagery for mapping invasive species has been validated by others [41-43].

To date, there are multiple satellite platforms that offer spatial resolutions higher than two meters. However, some researchers have expressed the need for even higher spatial resolutions for tracking plant invasions [44,45]. In that regard, UAS have gained popularity as a tool for invasive species detection due to high spatial and temporal resolution, relatively low cost, and their ability to survey locations quickly. Many have explored the use of UAS for identifying and monitoring invasive Phragmites [46-48]. Samiappan et al. (2017) [46] indicated that a maximum likelihood classifier with the use of textural algorithms could identify Phragmites from UAS imagery with average accuracies above $85 \%$. The use of texture to identify Phragmites from UAS imagery has been studied by others. Abeysinghe et al. (2019) [47] used image texture, normalized difference vegetation index (NDVI), and a canopy height model (CHM) to identify Phragmites within an estuary in Lake Erie. They noted the importance of using a CHM to identify Phragmites. Phragmites is taller than most wetland vegetation, and others have demonstrated the importance of using height for vegetation classification [49]. After patches had been identified, Tóth (2018) [48] demonstrated the potential for tracking and monitoring changes in distribution through the use of NDVI.

This study aimed to explore the capability of UAS for identifying Phragmites in Minnesota and Michigan using object-based image analysis. The impact of incorporating a CHM and SAR imagery within the classification was also explored. In this text, a CHM is used interchangeably with a normalized digital surface model (nDSM), and it is created by subtracting a digital elevation model (DEM) from a digital surface model (DSM). CHMs can be derived from lidar, SAR, and optical imagery. This study examined the use of both UAS-derived CHMs and stereo satellite-derived CHMs. We aimed to determine the effect of CHMs and SAR backscatter when identifying Phragmites from UAS imagery. The objectives of this study were: (i) determine whether Phragmites can be identified using only the spectral and textural information from three-band (i.e., red, green, and blue; RGB) UAS imagery; (ii) explore the effects of the addition of a canopy height model within the classification, both UAS-derived and stereo satellite-derived; (iii) evaluate whether the addition of SAR backscatter information improves the identification accuracy of Phragmites.

\section{Materials and Methods}

\subsection{Study Area}

Four Great Lakes coastal wetlands were used as study sites. Three study sites are located in Minnesota, USA (Figure 1), and one study site is located in Michigan, USA (Figure 2). Tallas Island (Figure 1A) is located roughly six miles southwest of Lake Superior in the St. Louis River Estuary. This 90-acre area consists of Tallas Island, a smaller island, and a portion of the Minnesota shoreline of the St. Louis River. Both islands are dominated by forest and shrub canopy. Shallow marsh plant communities are present on the borders of the islands and along the Minnesota shoreline. A road traverses the east-northeast edge of the study area, but the area otherwise has minimal development. 


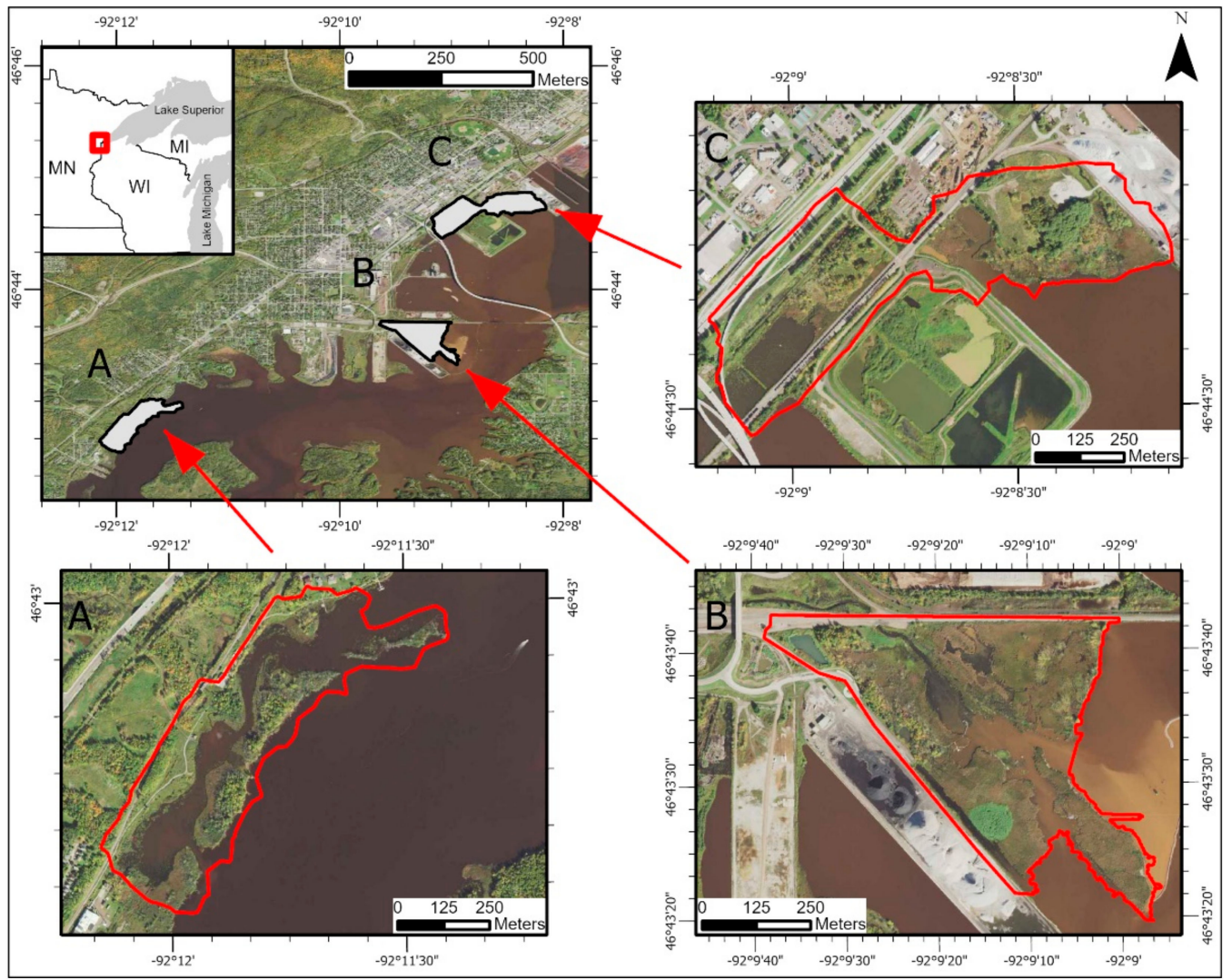

Figure 1. Study sites located in the St. Louis River Estuary in Duluth, Minnesota, USA: (A) Tallas Island, (B) Grassy Point Park, and (C) Hallett Dock.

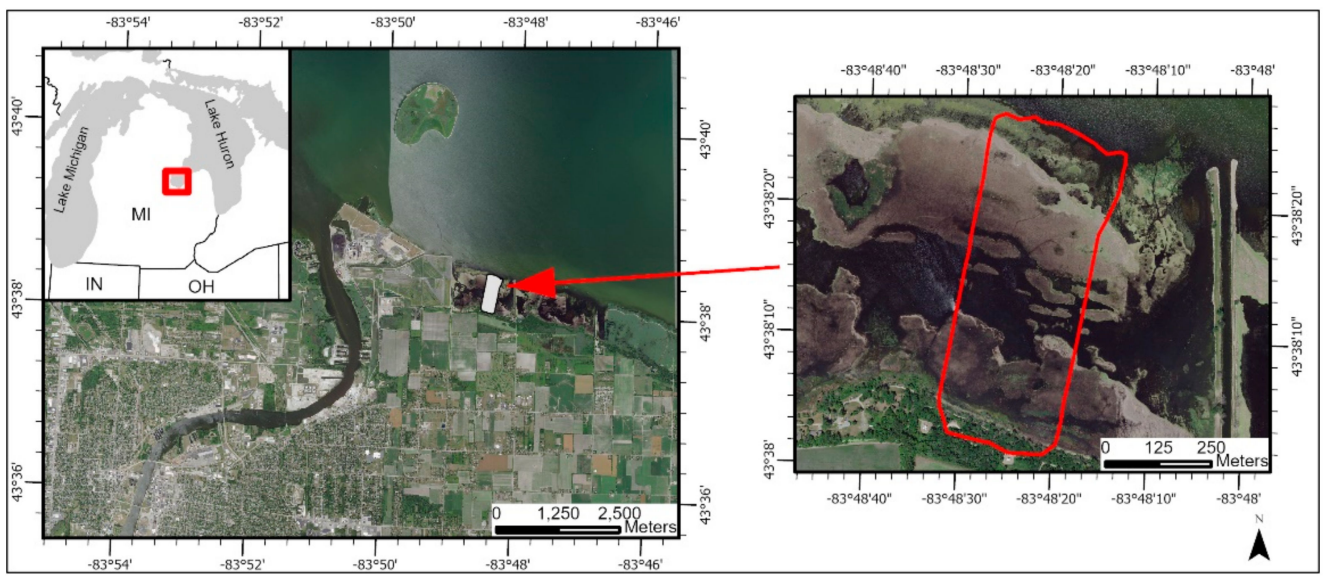

Figure 2. Study site located in Saginaw Bay, Michigan, USA.

Grassy Point Park (Figure 1B) is a 71-acre wetland complex located in Duluth, Minnesota along the St. Louis River. Grassy Point Park, located roughly four miles from Lake Superior, is the point where Keene Creek meets the St. Louis River. Grassy Point is heavily influenced by industrial land use. The park was the site of sawmilling operations that dumped wood waste into the estuary during the 19th century [50]. Currently, the complex is bordered by a railroad line, shipping channel, and a coal dock. Grassy Point has six different plant communities within the basin, including: seasonally flooded basin, shallow marsh, deep marsh, shallow open water, shrub swamp, and wooded swamp. Within this basin there are known patches of Phragmites, Typha spp. (cattails), Alnus spp. (alder), and other woody vegetation. Typha spp. is the most dominant vegetation type. 
Located approximately one mile northeast of Grassy Point Park is the second study area, Hallett Dock (Figure 1C). Hallett Dock is a 101-acre wetland complex located within the St. Louis River Estuary. A railway splits the complex in two, with both sections further segmented by gravel roads. The Hallett Dock study area is bordered to the north by U.S. Highway 35, a shipping dock to the northeast, and the St. Louis River to the south and southeast. Five plant communities are present within this complex including: shallow open water, seasonally flooded wetland, shallow marsh, hardwood wetland, and open water.

The final study area is located in Saginaw Bay, Michigan (Figure 2). The study area consists of the Lake Huron shoreline and emergent vegetation extending out into Saginaw Bay. Saginaw Bay has been an area of active Phragmites management in the Great Lakes Basin. A majority of this study area is dominated by standing, dead Phragmites stems. Vegetation on the shoreline is dominated by tree and shrub species. Non-Phragmites herbaceous vegetation has limited distribution within the study area and is mainly contained to the forest-water boundary. All vegetation not on the shore was flooded during data acquisition. The Saginaw Bay site was included due to minimal UAS acquisitions over Phragmites in the St. Louis River Estuary. It provided another Great Lakes coastal wetland testing location with environmental characteristics similar to those found near the three Minnesota study sites.

Living patches of Phragmites are present in two of the four study areas (Figure 3). Three patches of Phragmites exist within Grassy Point Park (Figure 3A). One patch is located in the bottom center of the park, one patch is interspersed with alder trees at the end of the canal, and the third is located along the shoreline of a basin in the northwest corner of the park. The distribution of Phragmites within Grassy Point Park is contained to these three patches. Saginaw Bay, although dominated by dead Phragmites, contains five patches of living Phragmites (Figure 3B). There are no populations of Phragmites in either the Tallas Island or Hallett Dock study areas. Both Tallas Island and Hallett Dock were selected to test for commission errors.

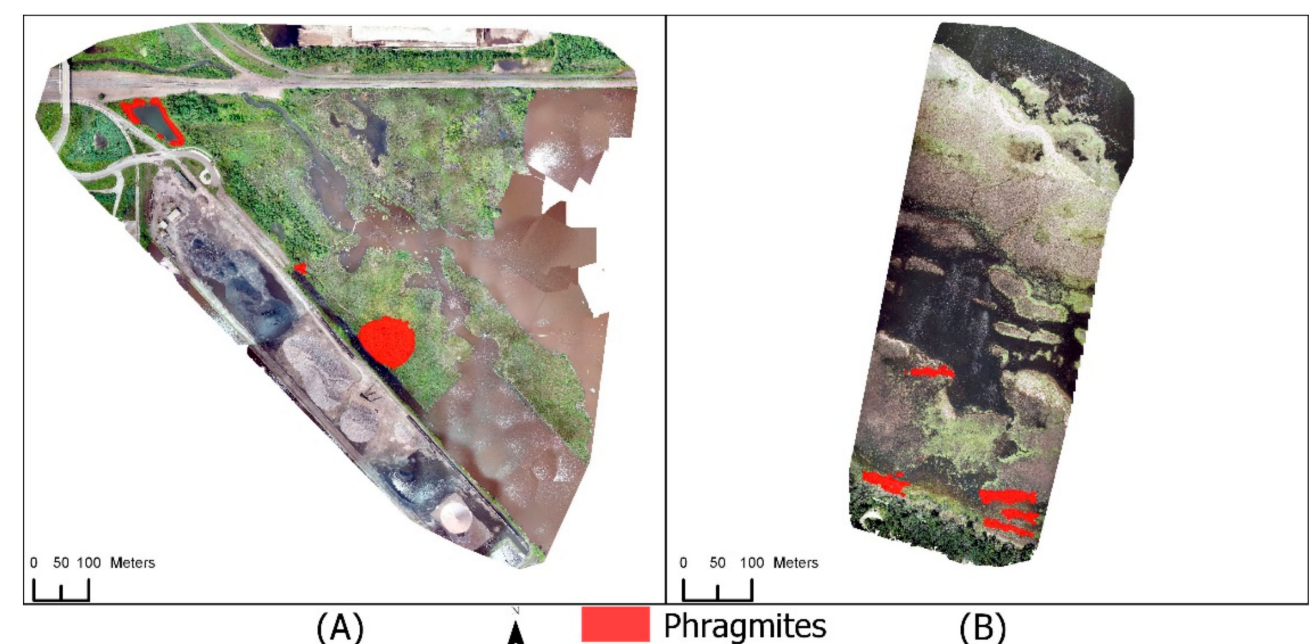

Figure 3. Known patches of Phragmites within the (A) Grassy Point Park study site and (B) the Saginaw Bay site. Three patches are present in Grassy Point Park, while five patches are present in the Saginaw Bay study site.

\subsection{Image Preprocessing}

\subsubsection{Optical Imagery}

UAS imagery over Grassy Point Park was acquired on two separate dates (Table 1). The first acquisition was completed by the Natural Resources Research Institute (NRRI) GIS Lab of the University of Minnesota Duluth in August of 2017. A Canon PowerShot S110 was used on a senseFly eBee UAS at $117 \mathrm{~m}$ above ground level (AGL) to achieve a spatial resolution of $4.2 \mathrm{~cm}$. Images were collected using 70\% endlap and sidelap. The University of 
Minnesota Remote Sensing and Geospatial Analysis Lab (UMN RSGAL) collected imagery over all three Minnesota study areas in August of 2018. A Microdrones MD4-1000 UAS equipped with a Sony A6300 camera was used to acquire images at roughly $121 \mathrm{~m}$ AGL. An endlap of $85 \%$ and a sidelap of $65 \%$ was used for these image acquisitions. The Grassy Point Park collection had a spatial resolution of $2.6 \mathrm{~cm}$, the Hallett Dock collection had a spatial resolution of $2.5 \mathrm{~cm}$, and the Tallas Island collection had a spatial resolution of $2.6 \mathrm{~cm}$. The Saginaw Bay study area was collected by the Michigan Technological Research Institute (MTRI) in August of 2018 using a DJI Mavic Pro with the stock camera. Images were acquired at about $100 \mathrm{~m}$ AGL with $70 \%$ endlap and sidelap, resulting in a spatial resolution of $3.3 \mathrm{~cm}$. Spectral resolution of each acquisition was limited to only the red, green, and blue spectral bands. Physical ground control points were not used during any acquisition. All UAS images were georeferenced, mosaicked, and a 3D point cloud was created in Pix4Dmapper (v. 4.2.27) [51]. The derived UAS point clouds were cleaned using rapidlasso LAStools (v. 170313) [52]. Noise points were removed using the lasnoise tool, and all points below mean water level were dropped.

Table 1. Collection parameters for each flight.

\begin{tabular}{|c|c|c|c|c|c|c|c|}
\hline \multicolumn{8}{|c|}{ Collection Parameters } \\
\hline $\begin{array}{l}\text { Study } \\
\text { Area }\end{array}$ & Year & Vehicle & Sensor & Altitude & Endlap & Sidelap & Resolution \\
\hline $\begin{array}{l}\text { Tallas } \\
\text { Island }\end{array}$ & 2018 & $\begin{array}{l}\text { Microdrone } \\
\text { MD4-1000 }\end{array}$ & Sony A6300 & $121 \mathrm{~m}$ & $85 \%$ & $65 \%$ & $2.6 \mathrm{~cm}$ \\
\hline $\begin{array}{l}\text { Grassy } \\
\text { Point Park }\end{array}$ & 2017 & senseFly eBee & $\begin{array}{c}\text { Canon } \\
\text { PowerShot } \\
\text { S110 }\end{array}$ & $117 \mathrm{~m}$ & $70 \%$ & $70 \%$ & $4.2 \mathrm{~cm}$ \\
\hline $\begin{array}{l}\text { Grassy } \\
\text { Point Park }\end{array}$ & 2018 & $\begin{array}{l}\text { Microdrone } \\
\text { MD4-1000 }\end{array}$ & Sony A6300 & $121 \mathrm{~m}$ & $85 \%$ & $65 \%$ & $2.6 \mathrm{~cm}$ \\
\hline $\begin{array}{l}\text { Hallett } \\
\text { Dock }\end{array}$ & 2018 & $\begin{array}{l}\text { Microdrone } \\
\text { MD4-1000 }\end{array}$ & Sony A6300 & $121 \mathrm{~m}$ & $85 \%$ & $65 \%$ & $2.5 \mathrm{~cm}$ \\
\hline $\begin{array}{l}\text { Saginaw } \\
\text { Bay }\end{array}$ & 2018 & $\begin{array}{l}\text { DJI Mavic } \\
\text { Pro }\end{array}$ & $\begin{array}{l}\text { Stock } \\
\text { Camera }\end{array}$ & $100 \mathrm{~m}$ & $70 \%$ & $70 \%$ & $3.3 \mathrm{~cm}$ \\
\hline
\end{tabular}

\subsubsection{Lidar}

Lidar ground elevation data were used for the creation of the CHMs. Minnesota and Michigan have freely available lidar datasets accessible through OpenTopography (https:/ / opentopography.org/ (accessed on 1 September 2019)). The Grassy Point Park, Hallett Dock, and Tallas Island study areas (St. Louis County, Minnesota, USA) were flown in the fall of 2012. Phragmites was standing and robust during the time of fall acquisition. The Saginaw Bay study site in Bay County, Michigan was flown in April of 2015. Despite the collection occurring before the growing season, individual Phragmites plants were still standing during the time of acquisition because Phragmites stems remain standing year-round. Leaves were also present on the stems, but the density of vegetation was lower than it is during peak growing season. Minnesota lidar elevations used the North American Vertical Datum of 1988 (NAVD88) referencing Geoid09, while the Michigan lidar elevations used NAVD88 referencing Geoid12b. After the removal of noise points, a DEM was created for each study site using rapidlasso LAStools [52]. Classified ground points were used exclusively for DEM creation except for Grassy Point Park. A vendor error misclassified the ground points of the southeast island in Grassy Point Park as water. Points classified as water were used in the creation of the Grassy Point Park DEM to correct for this error. The resulting DEMs had a spatial resolution of $1 \mathrm{~m}$. 


\subsubsection{Synthetic Aperture Radar}

Images from RADARSAT-2, a Canadian Space Agency sensor operating at a frequency of $5.4 \mathrm{GHz}$, were used in this study. Selected images were collected over the Minnesota study areas on 3 August 2017 and 8 August 2018 with incidence angles of 29.97 degrees. A single image was acquired over the Saginaw Bay study area on 11 August 2018 with an incidence angle of 25.42 degrees. Acquisitions were collected in the wide fine quad mode. The images were radiometrically calibrated, speckle filtered using a $3 \times 3$ Lee filter [53], converted to sigma naught $\left(\sigma^{\circ}\right)$, and geometrically corrected. Final image resolution was $9.45 \mathrm{~m}$. The horizontal send-horizontal receive $(\mathrm{HH})$ polarization was selected for identifying Phragmites due to the stronger response of double-bounce scattering in flooded vegetation [54,55]. All processing of the RADARSAT-2 imagery was completed using the Sentinel-1 Toolbox (v. 6.0.6) [56] in the ESA Sentinel Application Platform (SNAP) (v. 6.0.7) software [57].

\subsubsection{Commercial Satellite Stereo Retrievals}

Digital surface models (DSMs) were created by the University of Minnesota Polar Geospatial Center from DigitalGlobe, Inc. imagery. The panchromatic bands of stereo image pairs were processed using the surface extraction from TIN-based search-space minimization (SETSM) algorithm [58]. The resulting DSMs had a spatial resolution of $50 \mathrm{~cm}$. The selection of DSMs for this study was based on the acquisition date of the underlying stereo images. Priority was given to DSMs created during the growing season of the same year as the UAS imagery. Hallett Dock and Tallas Island used a single DSM created from a stereo pair of WorldView-2 images collected on 27 August 2018. The Saginaw Bay study area used a DSM created from a stereo pair of WorldView-2 images collected on 19 August 2018. No suitable stereo imagery was available for the 2017 UAS acquisition over Grassy Point due to persistent cloud cover.

The SETSM algorithm outputs products in ellipsoidal height using the WGS84 ellipsoid. A transformation from ellipsoidal height to orthometric height was completed using GDAL (v. 3.0.2) [59] to match the lidar. The DSM for Hallett Dock and Tallas Island was then adjusted using published vertical geodetic monuments. A linear regression was created between the geodetic monuments and the estimated DSM values. The regression equation was applied to the transformed DSM through the Raster Calculator tool in ESRI's ArcMap 10.7 software [60]. Few published vertical geodetic monuments were present around the Saginaw Bay study area. Instead, road points were selected from a lidar DEM to be used in the linear regression.

\subsubsection{UAS Point Cloud Adjustment}

For the creation of CHMs, the UAS point clouds needed to be adjusted to match the vertical reference system of the lidar. This adjustment was done in Pix4Dmapper [51] through the use of manually digitized vertical control points. Easily discernible locations that were selected in the UAS imagery had their elevation values gathered from the lidarderived DEMs. All selected vertical control points were over pavement, gravel, or bare earth. However, floating debris was used in the Saginaw Bay study area due to minimal bare earth coverage. Points identified through floating debris used an elevation of mean water level. Five vertical control points were used for the Grassy Point acquisitions, seven points were used for the Hallett Dock acquisition, six points were used for Tallas Island acquisition, and six points were used for the Saginaw Bay acquisition. All points were distributed around each wetland complex and manually identified in at least three separate images.

Pix4Dmapper [51] has three options when defining a vertical coordinate system: (1) Use one of three reference geoids (EGM1984, EGM1996, EGM2008); (2) specify a constant geoid height above the WGS84 Ellipsoid; (3) an arbitrary vertical coordinate system. Selecting the arbitrary vertical coordinate system results in Pix4Dmapper [51] adjusting the vertical values of the point cloud to match the vertical values of the vertical control points. 
This approach allows for both the co-registration of the point cloud to the lidar DEM and the adjustment of the point cloud to match the vertical coordinate system of the vertical control points. In this case, the UAS point cloud was co-registered to the lidar DEM and adjusted to NAVD88. Geoid09 was used for the Minnesota study sites, and Geoid12b was used for the Michigan study site. DSMs were then created using rapidlasso LAStools [52]. The spatial resolution of each DSM matched the spatial resolution of the corresponding optical imagery.

\subsection{Classification}

An object-based image analysis (OBIA) classifier was selected for this study. OBIA has been used frequently for wetland mapping and invasive species identification [61-66]. This classification approach has the advantage of incorporating shape, size, and contextual information in addition to spectral and textural information, which produces better approximations of real-world features $[67,68]$. Additionally, data inputs are not confined to use of the same sensor or resolution. The ability to include multiple data types into object-based classifications frequently results in higher mapping accuracy compared to pixel-based classifications [67,68].

Some researchers that have used OBIA for identifying vegetation performed one segmentation, then allowed a machine-learning algorithm to classify the objects thereafter $[18,47,63]$. Doing so does not allow for the incorporation of contextual information within the OBIA classification. Our process differs in that we used an iterative approach without a machine-learning classifier to identify Phragmites. This means that objects were merged and further segmented to delineate patch boundaries. Iterative approaches allow for the inclusion of expert knowledge into the classifier as well as reducing oversegmentation and under-segmentation of objects [69].

Classifications were completed using the Trimble eCognition Developer (v. 9.4) software [70]. Three object-based classifiers, or rule sets, were built to answer the study questions. The first classifier used only the optical imagery to identify Phragmites, the second classifier utilized a CHM with the optical imagery, and the third classifier included the RADARSAT-2 HH polarization with the CHM and optical imagery. Each of the three classifiers followed the same pattern. First, new temporary raster layers were created, followed by the removal of No Data areas. The first temporary raster layer was the visibleband difference vegetative index (VDVI). VDVI uses the red, green, and blue bands to calculate a vegetative health index similar to NDVI and ranges from -1 to 1 [71]. VDVI was calculated using the following mathematical formula:

$$
\frac{(2 * \text { green })-\text { red }- \text { blue }}{(2 * \text { green })+\text { red }+ \text { blue }}
$$

Additionally, a CHM was created by subtracting a lidar-derived DEM from a DSM. The CHM creation was only present in the two classifiers that use height of vegetation to identify Phragmites. No Data values were removed using a series of quadtree segmentations.

Data layers were initially segmented using the multi-resolution segmentation algorithm at a scale parameter of 30 , along with a shape parameter of 0.3 and compactness parameter of 0.5 . The scale parameter determines the size of the resulting objects, e.g., larger values for scale parameter produce larger image objects and smaller values produce smaller image objects. The shape parameter determines the influence of shape and color for image object creation. Larger values for shape will result in shape having more influence than color for object creation. Smaller values for shape will result in color having a higher weight for image object creation. The compactness parameter determines the smoothness or compactness of the image objects. Higher values of compactness result in more compact objects, while lower values will result in smoother objects. Parameter values used in this study were determined through trial and error.

Initial image objects were assigned to either vegetation or not vegetation classes based on the mean VDVI of the entire scene. Objects below the mean VDVI were placed into the not vegetation class while objects above the scene mean were placed into the 
vegetation class. The objects in the vegetation class were merged and re-segmented using the multi-resolution segmentation algorithm at a scale parameter of 10 . A shape parameter of 0.3 and compactness parameter of 0.5 were used for the segmentation. Phragmites was initially identified from the vegetation class using texture, specifically the grey-level cooccurrence matrix (GLCM) homogeneity algorithm. Texture has been used by others to identify Phragmites [46,47] and other invasive plants [72-75]. The GLCM homogeneity algorithm multiplies a pixel's grey level value based on the neighboring pixel's grey level. Pixels sharing the same grey level are multiplied by one, while pixels with different grey levels exponentially decrease by a factor dependent on the extent of the difference in grey level [76]. All layers were used in the texture calculation. Objects with a rough texture, or a low GLCM homogeneity value, were assigned to the Phragmites class.

Removal of canopy gaps and refinement of object shapes was completed after the initial identification of Phragmites. It is unlikely that vegetation within a patch of Phragmites is another species due to the density at which Phragmites grows. Therefore, all vegetation objects completely surrounded by the Phragmites class were reassigned as Phragmites. The objects identified as Phragmites were further defined through the use of the GLCM contrast algorithm. This algorithm is similar to GLCM homogeneity, but it highlights objects with textures different from their neighbors [76]. Finally, objects with small areas were removed. Phragmites patches are likely to be multiple square meters in size. Anything below that size was deemed improbable to detect. The resulting classifications had two final classes, Phragmites and Not Phragmites.

All OBIA classifiers were trained on the 2018 UAS collection of Grassy Point Park because it was the first available acquisition with known Phragmites patches. Creation of each rule set was done through trial and error. Four classifications were completed for the Hallett Dock, Tallas Island, and Saginaw Bay study areas (Tables 2 and 3). This included: (1) strictly RGB UAS imagery; (2) RGB UAS imagery and a CHM created using a UAS-derived DSM; (3) RGB UAS imagery and a CHM created using a stereo satellite-derived DSM; (4) RGB UAS imagery, RADARSAT-2 HH polarization, and a UAS-derived CHM. Three classifications were completed using the 2017 Grassy Point Park collection (Table 3): (1) strictly RGB UAS imagery; (2) RGB UAS imagery and a CHM created using a UAS-derived DSM; 3) RGB UAS imagery, RADARSAT-2 HH polarization, and a UAS-derived CHM. 


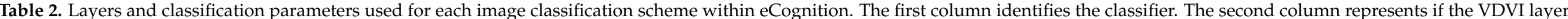

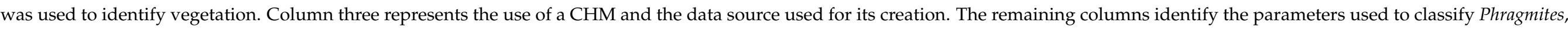

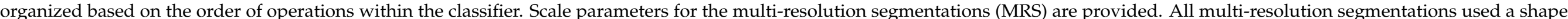

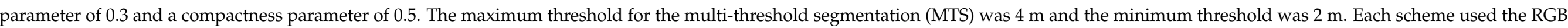

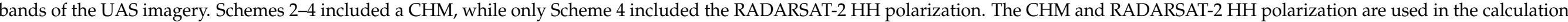
of GLCM homogeneity and contrast if the layer is present in the classifier.

\begin{tabular}{|c|c|c|c|c|c|c|c|c|c|c|c|c|c|}
\hline \multirow[b]{2}{*}{ Scheme } & \multicolumn{13}{|c|}{ Parameters } \\
\hline & VDVI & $\mathrm{CHM}$ & $\begin{array}{c}\text { MRS } \\
\text { (Scale 30) } \\
\end{array}$ & MTS & $\begin{array}{c}\text { MRS } \\
\text { (Scale 10) }\end{array}$ & $\begin{array}{c}\text { MRS } \\
\text { (Scale 100) } \\
\end{array}$ & $\begin{array}{c}\text { GLCM } \\
\text { Homogeneity }\end{array}$ & $\begin{array}{c}\text { Max } \\
\text { Difference }\end{array}$ & Brightness & $\begin{array}{l}\text { Border to } \\
\text { Phragmites }\end{array}$ & $\begin{array}{c}\text { GLCM } \\
\text { Contrast }\end{array}$ & $\begin{array}{c}\text { Area } \\
\text { (Pixel) }\end{array}$ & RADARSAT-2 HH \\
\hline 1 & $X$ & & $X$ & & $X$ & & $X$ & & & $X$ & $X$ & $X$ & \\
\hline 2 & $X$ & UAS & $X$ & $X$ & $X$ & $X$ & $X$ & $X$ & $X$ & $X$ & $X$ & $X$ & \\
\hline 3 & $x$ & Satellite & $x$ & $\mathrm{X}$ & $x$ & $x$ & $\mathrm{X}$ & $x$ & $\mathrm{X}$ & $x$ & $\mathrm{X}$ & $x$ & \\
\hline 4 & $X$ & UAS & $X$ & $x$ & $X$ & $X$ & $X$ & $X$ & $X$ & $X$ & $x$ & $X$ & $X$ \\
\hline
\end{tabular}


Table 3. Classification schemes used at each study area. This includes: Scheme (1) strictly the RGB UAS imagery using rule set 1 ; Scheme (2) RGB UAS imagery and a UAS-derived CHM using rule set 2; Scheme (3) RGB UAS imagery and a stereo satellite-derived CHM using rule set 2; Scheme (4) RGB UAS imagery, UAS-derived CHM, and the RADARSAT-2 HH polarization using rule set 3 . Scheme (3) was not used for Grassy Point Park due to data unavailability.

\begin{tabular}{ccccc}
\hline & \multicolumn{4}{c}{ Classification Scheme } \\
\cline { 2 - 5 } Study Area & Scheme 1 & Scheme 2 & Scheme 3 & Scheme 4 \\
\hline Grassy Point Park & $\mathrm{X}$ & $\mathrm{X}$ & $\mathrm{X}$ & $\mathrm{X}$ \\
Hallett Dock & $\mathrm{X}$ & $\mathrm{X}$ & $\mathrm{X}$ & $\mathrm{X}$ \\
Tallas Island & $\mathrm{X}$ & $\mathrm{X}$ & $\mathrm{X}$ & $\mathrm{X}$ \\
Saginaw Bay & $\mathrm{X}$ & $\mathrm{X}$ & \\
\hline
\end{tabular}

Differences between Rule Sets

Although each rule set follows the same scheme, there were slight differences between them. The biggest difference was the inclusion of a CHM in the second and third classifier. This allowed for partitioning of vegetation into different height classes. A multi-threshold segmentation was used to assign objects with a mean height from two to four meters as potential Phragmites. Remaining vegetation objects with a mean height below two meters were merged then segmented using a multi-resolution segmentation at a scale parameter of 100 . The multi-resolution segmentation used a shape parameter of 0.3 and compactness parameter of 0.5. Vegetation objects touching the potential Phragmites class were reassigned as potential Phragmites. The potential Phragmites class was further refined following the procedure described above. This allowed for the edges of Phragmites patches to be included. Two additional algorithms were used following the GLCM homogeneity algorithm to shape Phragmites objects: max difference and brightness. The max difference algorithm looks at the differences in all layers between neighboring objects. Brightness corresponds to how bright an object appears, e.g., white objects will be brighter than black objects. The max difference and brightness algorithms were used to fill gaps in the canopy. These two algorithms were not included in the first classifier due to overestimating Phragmites without a height threshold. Lastly, for the third classifier, the mean RADARSAT-2 HH backscatter intensity was used to remove incorrectly identified Phragmites objects. This was the only difference between the second and third classifier.

The second and third classifiers included the surface models and the RADARSAT-2 $\mathrm{HH}$ polarization layers when calculating texture. Surface models were included because height is representative of surface texture due to shadowing from taller vegetation. The RADARSAT-2 HH polarization was included because backscatter intensity is directly related to structural properties of surface scatterers [33]. Leaf orientation, stem density, and other physical characteristics of plants impact the backscatter intensity, and these physical characteristics are also related to surface texture.

\subsection{Accuracy Assessment}

Phragmites patch locations in the St. Louis River Estuary were determined through survey data provided by the Great Lakes Indian Fish and Wildlife Commission (GLIFWC), verified populations through EDDMapS, and populations reported to the Minnesota Aquatic Invasive Species Research Center (MAISRC) (https: / / www.maisrc.umn.edu/phragmitesmap (accessed on 1 September 2019)). The boundaries of the three identified patches in Grassy Point Park were manually digitized using visual interpretation and the UAS imagery. No populations were reported in Tallas Island or Hallett Dock. Visual interpretation of both the Hallett Dock and Tallas Island imagery corroborated the absence of Phragmites within these two study areas. Saginaw Bay did not have point data corresponding to Phragmites locations. Personal communication with the provider of the Saginaw Bay UAS imagery confirmed the presence of Phragmites within the study area. The Saginaw Bay UAS imagery was visually interpreted, and the living patches of Phragmites were manually 
digitized. Visual interpretation of the UAS imagery was used to confirm no regrowth of Phragmites within the standing, dead Phragmites stalks.

For the Grassy Point Park and Saginaw Bay study sites, 50 points were randomly generated within the digitized Phragmites patch boundaries, and 80 points were randomly generated outside of the digitized Phragmites patch boundaries (Figure 4). The number of assessment points in the Phragmites class was selected due to the minimal area of Phragmites within the study areas, following the recommendation of Congalton (1991) [77] and Congalton and Green (2019) [78] for the minimum number of points per class. For study areas with no known Phragmites, a total of 130 points were randomly generated within the extent of the study area (Figure 4). Each randomly generated point was then examined by a Phragmites expert who visually interpreted the UAS imagery to determine whether the point fell on Phragmites. Two Not Phragmites validation points in Hallett Dock were incorrectly identified as Phragmites by the expert conducting the validation. Physical surveying of the area by the GLIFWC showed no Phragmites in Hallett Dock so those two points were discarded. A number of points generated in known Phragmites patches fell within canopy gaps. This resulted in fewer than 50 assessment points in the Phragmites class for both Grassy Point Park and Saginaw Bay (Table 4). However, this was deemed acceptable due to the small total area of Phragmites in each of these study sites. Increasing the number of assessment points for the Phragmites class in this situation would have resulted in points being located closely to other assessment points, as well as potentially inflating accuracy.

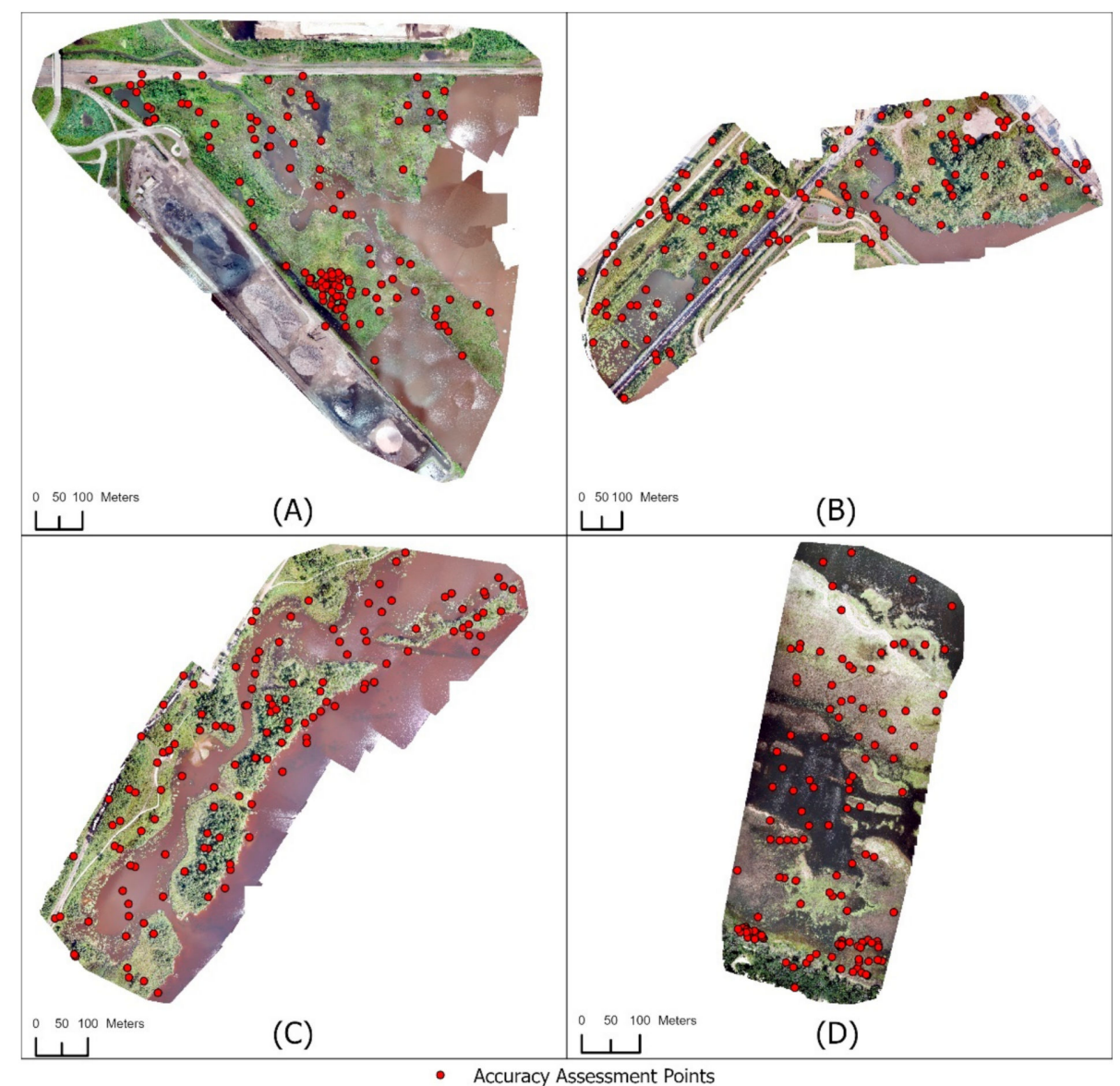

Figure 4. Location of the randomly generated validation points for each study area. Fifty points were randomly generated within the boundaries of the Phragmites patches in both (A) Grassy Point Park and (D) Saginaw Bay, while 80 points were generated outside of the patch boundaries. One hundred and thirty points were randomly generated within (B) Hallett Dock and (C) Tallas Island. 
Table 4. Number of validation points randomly generated by class in each study area. No validation points were generated for the Phragmites class in Tallas Island and Hallett Dock due to no populations of Phragmites existing within those study areas. Fifty validation points were originally generated for Phragmites in Grassy Point Park and Saginaw Bay, but were reduced due to points falling within gaps in the Phragmites patches.

\begin{tabular}{ccc}
\hline & \multicolumn{2}{c}{ Number of Validation Points } \\
\cline { 2 - 3 } Study Area & Phragmites & Not Phragmites \\
\hline Grassy Point Park & 45 & 85 \\
Hallett Dock & 0 & 128 \\
Saginaw Bay & 37 & 93 \\
Tallas Island & 0 & 130 \\
\hline
\end{tabular}

A confusion matrix was created for each classification, and the individual producer's and user's accuracies for each class were calculated [78]. Only the accuracy of the Not Phragmites class in both the Tallas Island and Hallett Dock study areas was calculated. Accuracies for the Phragmites class were not calculated for Hallett Dock and Tallas Island due to the absence of Phragmites within those two sites. To account for this, the total area of misclassified vegetation was calculated for Hallett Dock and Tallas Island to provide another accuracy metric. Total area of misclassified vegetation was calculated by the division of the area of the Phragmites class by the total area of the study site. Combined producer's and user's accuracy of the Phragmites class was calculated for three of the four classifications. A confusion matrix was used to calculate the combined accuracy for the three classifications, which was created by combining the accuracy assessment points from each of the four study sites. The combined accuracy for the classification utilizing a satellite-derived CHM (Scheme 3, Tables 2 and 3) was not calculated due to no classification over Grassy Point Park.

\section{Results}

\subsection{RGB Spectral Bands and Textural Algorithms for the Identification of Phragmites}

The identification of Phragmites using the spectral and textural information from the RGB UAS imagery was tested in the four study areas (Scheme 1, Tables 2 and 3). User's and producer's accuracies were calculated for each class (Phragmites, Not Phragmites) using the independently validated points (Table 5). The resulting classification using only the RGB UAS imagery is shown in Figure 5.

Table 5. Validated assessment points for each study area for the classification using only the RGB UAS imagery. Points are split by class (Phragmites, Not Phragmites) and if they were correctly identified (Correct, Incorrect).

\begin{tabular}{ccccc}
\hline & \multicolumn{2}{c}{ Phragmites Class } & \multicolumn{2}{c}{ Not Phragmites Class } \\
\cline { 2 - 5 } Study Area & Correct & Incorrect & Correct & Incorrect \\
\hline Grassy Point Park & 45 & 0 & 53 & 32 \\
Hallett Dock & - & - & 85 & 43 \\
Saginaw Bay & 33 & 4 & 57 & 36 \\
Tallas Island & - & - & 67 & 63 \\
\hline
\end{tabular}




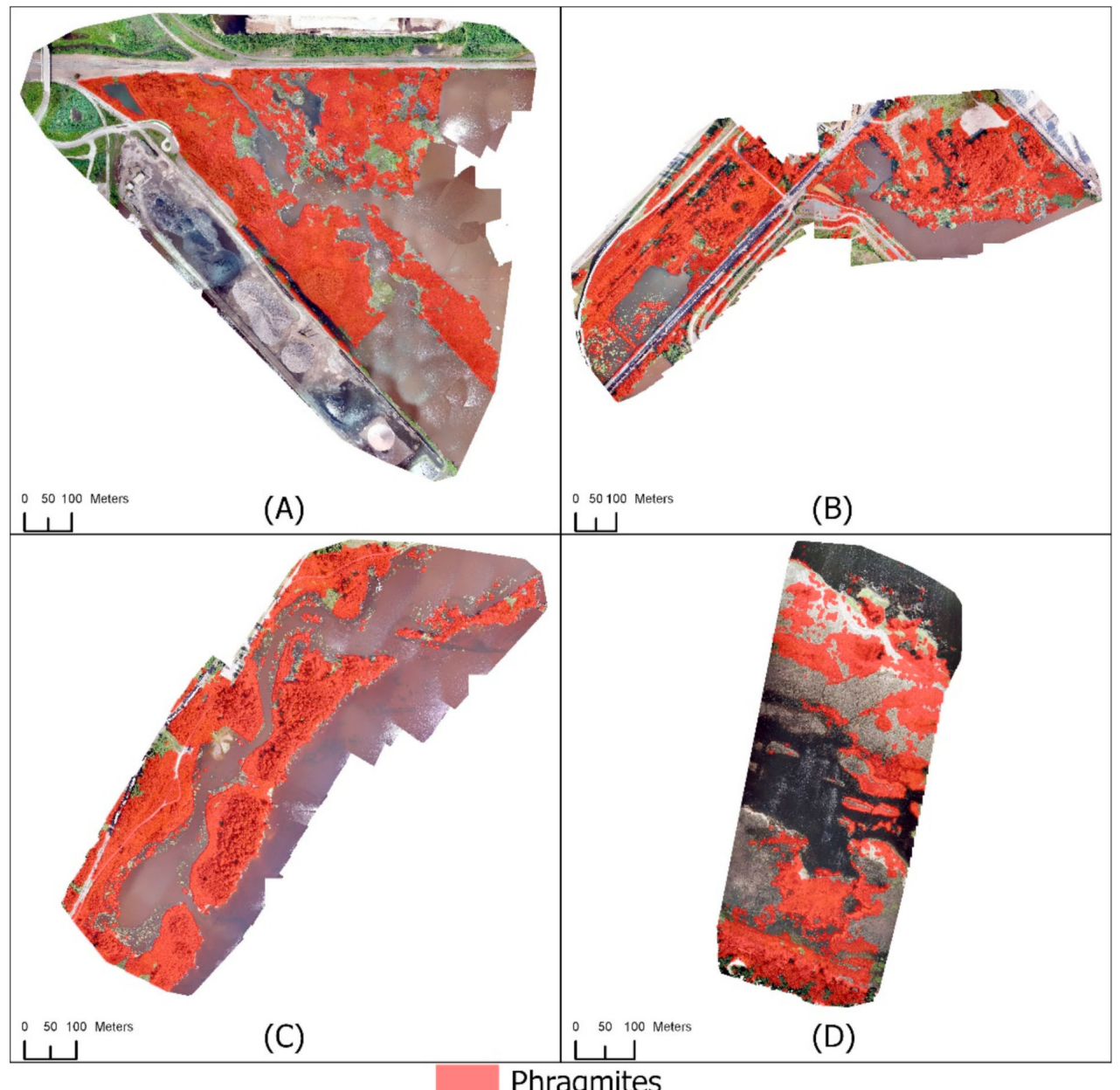

Phragmites

Figure 5. Mapping Phragmites using RGB UAS imagery without the use of a CHM or RADARSAT-2 HH polarization for (A) Grassy Point Park, (B) Hallett Dock, (C) Tallas Island, and (D) Saginaw Bay.

Classifications using only the spectral and textural information from the RGB imagery (Scheme 1, Tables 2 and 3) exhibited low user's accuracies for the Phragmites class (Table 6). The extent of Phragmites in each study area was significantly overestimated. All of the Phragmites validation points were correctly identified in Grassy Point Park, but 32 of the 85 Not Phragmites validation points were incorrectly identified as Phragmites. This resulted in a user's accuracy of $58 \%$ for the Phragmites class. Saginaw Bay had a user's accuracy of $48 \%$. Thirty-three of the 37 Phragmites validation points were correctly identified at Saginaw Bay, but 36 Not Phragmites validation points were incorrectly classified as Phragmites. A similar response of widespread misidentification was seen in the Hallett Dock and Tallas Island study areas. Roughly $28 \%$ of the Hallett Dock study site and 33\% of Tallas Island study site were misclassified as Phragmites. Forty-three of the 128 Not Phragmites validation points at Hallett Dock were incorrectly classified as Phragmites. Sixty-three of the 130 Not Phragmites validation points at Tallas Island were incorrectly classified as Phragmites. All study areas had user's accuracies above $90 \%$ for the Not Phragmites class. 
Table 6. Classification performance for all four study sites when using the RGB UAS imagery without the use of a CHM or RADARSAT-2 HH polarization. Producer's accuracy and user's accuracy are provided for each study site. Only the accuracy of the Not Phragmites class was calculated for Hallett Dock and Tallas Island. The combined accuracy of the Not Phragmites class was not calculated.

\begin{tabular}{lccccc}
\hline & \multicolumn{5}{c}{ Study Area } \\
\cline { 2 - 6 } Class & Grassy Point & Hallett Dock & Tallas Island & Saginaw Bay & Combined \\
\hline $\begin{array}{l}\text { Producer's } \\
\text { Accuracy (\%) }\end{array}$ & 100 & N/A & N/A & 89 & \\
$\begin{array}{l}\text { Phragmites } \\
\text { Not Phragmites }\end{array}$ & 62 & 66 & 52 & 61 & N/A \\
$\begin{array}{l}\text { User's Accuracy } \\
\text { (\%) }\end{array}$ & & & & & \\
Phragmites & 58 & N/A & N/A & 48 & 31 \\
Not Phragmites & 100 & 100 & 100 & 93 & N/A \\
\hline
\end{tabular}

Producer's accuracies were higher for the Phragmites class due to overestimation of Phragmites. The Phragmites class for Grassy Point Park had a producer's accuracy of $100 \%$, and the Phragmites class for Saginaw Bay had a producer's accuracy of 89\%. Four Phragmites validation points were incorrectly identified as Not Phragmites. Commission errors resulted in low producer's accuracies for the Not Phragmites class. The producer's accuracy of the Not Phragmites class for Grassy Point Park was 62\%, 66\% for Hallett Dock, 52\% for Tallas Island, and 61\% for Saginaw Bay.

Combined user's accuracies across all four sites for the Phragmites class was low. Consistent misidentification led to a user's accuracy of $31 \%$ for the Phragmites class. However, since most vegetation was classified as Phragmites, the Phragmites class had a producer's accuracy of $95 \%$.

\subsection{Incorporating CHMs for Phragmites Identification}

The four study areas were classified with the addition of a UAS-derived CHM (Figure 6) using Scheme 2 (Tables 2 and 3). Each classification was evaluated using the independently validated points (Table 7). Classifications using a UAS-derived CHM had higher accuracies than the classifications without a CHM (Table 8). Splitting the vegetation into different height thresholds allowed for trees, shrubs, and shorter vegetation to be classified correctly more often. The Phragmites class for Grassy Point Park had a user's accuracy of 92\% with three Not Phragmites validation points being incorrectly identified as Phragmites. Eleven Phragmites validation points were incorrectly identified as Not Phragmites resulting in a producer's accuracy of 76\% for Grassy Point Park's Phragmites class. Inaccuracy of patch extent caused most omission errors. All but one known Phragmites patch was identified in Grassy Point Park, which is interspersed with Alnus spp. The Phragmites patch interspersed with Alnus sp. was unlikely to be correctly identify due to the tree canopy cover. Commission errors were greatly reduced even without the correct classification of all Phragmites validation points. The user's accuracy for the Not Phragmites class was $88 \%$, and the producer's accuracy was $97 \%$. 


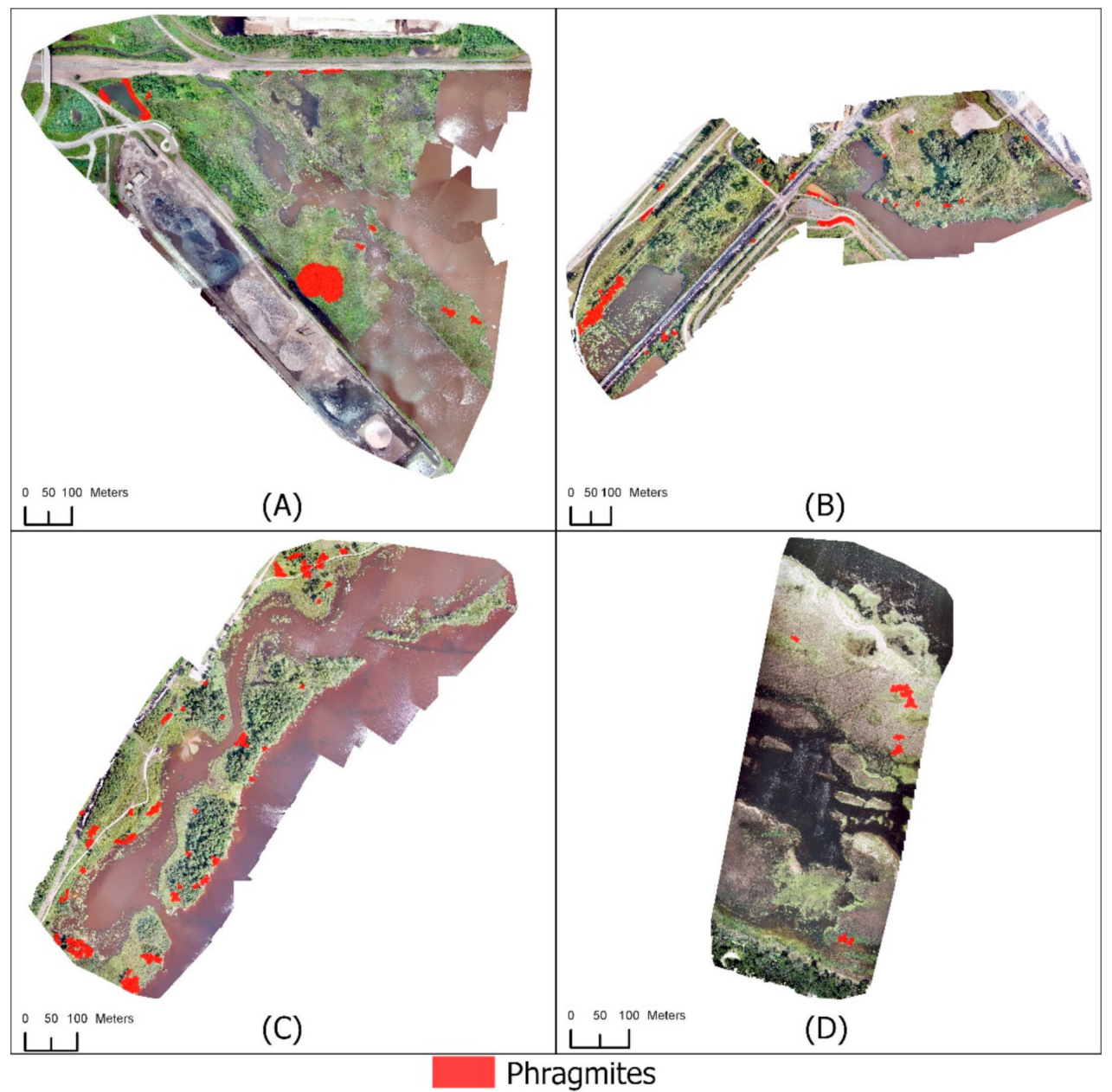

Figure 6. Mapping Phragmites using RGB UAS imagery with a UAS-derived CHM for (A) Grassy Point Park, (B) Hallett Dock, (C) Tallas Island, and (D) Saginaw Bay.

Table 7. Validated assessment points from each study area for the classification using the RGB UAS imagery and a UAS-derived CHM. Points are split by class (Phragmites, Not Phragmites) and if they were correctly identified (Correct, Incorrect).

\begin{tabular}{ccccc}
\hline & \multicolumn{2}{c}{ Phragmites Class } & \multicolumn{2}{c}{ Not Phragmites Class } \\
\cline { 2 - 5 } Study Area & Correct & Incorrect & Correct & Incorrect \\
\hline Grassy Point Park & 34 & 11 & 82 & 3 \\
Hallett Dock & - & - & 127 & 1 \\
Saginaw Bay & 1 & 36 & 93 & 0 \\
Tallas Island & - & - & 130 & 0 \\
\hline
\end{tabular}


Table 8. Classification performance for all four study sites when using the RGB UAS imagery with a UAS-derived CHM. Producer's accuracy and user's accuracy are provided for each study site. Only the accuracy of the Not Phragmites class was calculated for Hallett Dock and Tallas Island. The combined accuracy of the Not Phragmites class was not calculated.

\begin{tabular}{|c|c|c|c|c|c|}
\hline \multirow[b]{2}{*}{ Class } & \multirow[b]{2}{*}{ Grassy Point } & \multicolumn{4}{|c|}{ Study Area } \\
\hline & & Hallett Dock & Tallas Island & Saginaw Bay & Combined \\
\hline \multicolumn{6}{|c|}{$\begin{array}{l}\text { Producer's Accuracy } \\
(\%)\end{array}$} \\
\hline Phragmites & 76 & $\mathrm{~N} / \mathrm{A}$ & $\mathrm{N} / \mathrm{A}$ & 3 & 43 \\
\hline Not Phragmites & 97 & 99 & 100 & 100 & $\mathrm{~N} / \mathrm{A}$ \\
\hline \multicolumn{6}{|c|}{ User's Accuracy (\%) } \\
\hline Phragmites & 92 & $\mathrm{~N} / \mathrm{A}$ & $\mathrm{N} / \mathrm{A}$ & 100 & 90 \\
\hline Not Phragmites & 88 & 100 & 100 & 72 & $\mathrm{~N} / \mathrm{A}$ \\
\hline
\end{tabular}

This trend was consistent in the Hallett Dock and Tallas Island study areas. The Not Phragmites class at Hallett Dock had a user's accuracy of $100 \%$ and a producer's accuracy of $99 \%$. Only one Not Phragmites validation point was incorrectly classified as Phragmites. The Not Phragmites class of Tallas Island had a user's and producer's accuracy of $100 \%$. It is important to note that vegetation was still misidentified as Phragmites, potentially leading the accuracies at the Hallett Dock and Tallas Island locations to be falsely high. Including a UAS-derived CHM reduced the total misclassified area of Hallett Dock to $0.7 \%$ of the study site. Of the vegetation in Tallas Island, $1.1 \%$ was misidentified as Phragmites. A different result was seen at Saginaw Bay. Including a UAS-derived CHM reduced the classification accuracy. The Phragmites class had a user's accuracy of $100 \%$ and a producer's accuracy of 3\%. A single Phragmites validation point fell within the estimated Phragmites extent. All Not Phragmites validation points were correctly identified in Saginaw Bay.

Combined user's accuracy for the Phragmites class significantly improved (Table 8). Four Not Phragmites validation points were incorrectly classified as Phragmites resulting in a combined user's accuracy for $90 \%$. However, the omission of Phragmites at Saginaw Bay resulted in a combined producer's accuracy of $43 \%$ for the Phragmites class.

Three of the four study areas were classified with the addition of a satellite-derived CHM (Figure 7) using Scheme 3 (Tables 2 and 3). Classifications with a satellite-derived CHM resulted in slightly lower accuracies than the UAS-derived CHM (Tables 9 and 10). Hallett Dock had a user's accuracy of $100 \%$ and a producer's accuracy of $91 \%$ for the Not Phragmites class. Twelve of the 128 Not Phragmites validation points were incorrectly classified as Phragmites. An increase in misidentified vegetation was seen using a satellite-derived CHM. The total misclassified area of Hallett Dock was 9.1\% when using a satellite-derived CHM compared to the $0.7 \%$ when using a UAS-derived CHM. Commission errors were higher at forest boundaries, which are a result of a lower spatial resolution CHM. Tallas Island had comparable results to Hallett Dock when using a satellite-derived CHM. The user's accuracy for the Not Phragmites class was $100 \%$, and the producer's accuracy was $83 \%$. The total area of vegetation misclassified as Phragmites was $12.9 \%$ of the study site. Twenty-two of the $130 \mathrm{Not}$ Phragmites validation points were incorrectly classified as Phragmites. Similar to Hallett Dock, commission errors were frequent around forest boundaries. Saginaw Bay had a slight increase in classification accuracy when using a satellite-derived CHM compared to using a UASderived CHM. Phragmites was correctly identified in four of the five patches, but the shapes of the objects did not match the Phragmites extent. Six Not Phragmites validation points were incorrectly classified as Phragmites resulting in a user's accuracy of $57 \%$ for the Phragmites class. Twenty-nine of the 37 Phragmites validation points were incorrectly classified as Not Phragmites resulting in a producer's accuracy of $22 \%$. The Not Phragmites class had a user's accuracy of $75 \%$ and a producer's accuracy of $94 \%$. 


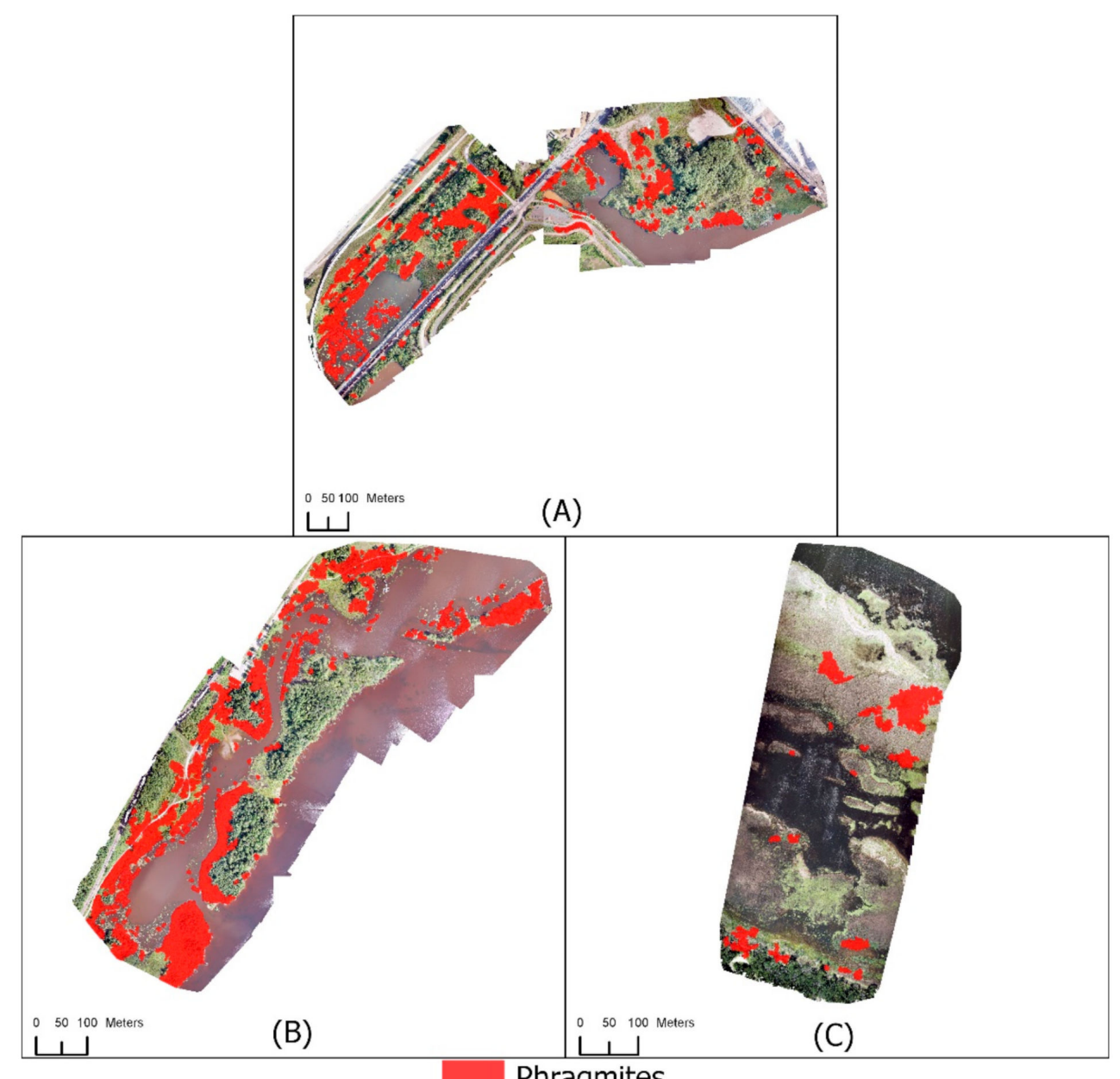

Phragmites

Figure 7. Mapping Phragmites using RGB UAS imagery with a satellite-derived CHM for (A) Hallett Dock, (B) Tallas Island, and (C) Saginaw Bay. DSMs were created by the Polar Geospatial Center from DigitalGlobe, Inc. imagery.

Table 9. Validated assessment points from each study area for the classification using the RGB UAS imagery and a satellite-derived CHM. Points are split by class (Phragmites, Not Phragmites) and if they were correctly identified (Correct, Incorrect).

\begin{tabular}{ccccc}
\hline & \multicolumn{2}{c}{ Phragmites Class } & \multicolumn{2}{c}{ Not Phragmites Class } \\
\cline { 2 - 5 } Study Area & Correct & Incorrect & Correct & Incorrect \\
\hline Hallett Dock & - & - & 116 & 12 \\
Saginaw Bay & 8 & 29 & 87 & 6 \\
Tallas Island & - & - & 108 & 22 \\
\hline
\end{tabular}


Table 10. Classification performance for all four study sites when using the RGB UAS imagery with a stereo satellite-derived CHM. Only the accuracy of the Not Phragmites class was calculated for Hallett Dock and Tallas Island.

\begin{tabular}{lccc}
\hline & \multicolumn{3}{c}{ Study Area } \\
\cline { 2 - 4 } Class & Hallett Dock & $\begin{array}{c}\text { Tallas } \\
\text { Island }\end{array}$ & Saginaw Bay \\
\hline $\begin{array}{l}\text { Producer's Accuracy (\%) } \\
\text { Phragmites }\end{array}$ & N/A & N/A & 22 \\
Not Phragmites & 91 & 83 & 94 \\
User's Accuracy (\%) & & & \\
Phragmites & N/A & N/A & 57 \\
Not Phragmites & 100 & 100 & 75 \\
\hline
\end{tabular}

\subsection{Including SAR for Phragmites Identification}

Each study area was classified with the addition of a UAS-derived CHM and the RADARSAT-2 HH polarization (Figure 8) using the rule set described above (Scheme 4, Tables 2 and 3). The satellite-derived CHM was not tested with the RADARSAT-2 HH polarization. Accuracies of classifications incorporating SAR performed comparable to classifications using only the UAS-derived CHM (Scheme 2, Tables 2 and 3) at the Minnesota study sites (Tables 11 and 12). Differences were the removal of misidentified objects and the changes to the object shapes. Four Not Phragmites validation points were misclassified as Phragmites resulting in a user's accuracy of $90 \%$ for the Grassy Point Park Phragmites class. Eleven of the 45 Phragmites validation points were omitted resulting in a producer's accuracy of $76 \%$ for the Grassy Point Park Phragmites class. The Not Phragmites class had a user's accuracy of $88 \%$ and a producer's accuracy of $95 \%$. Accuracies for Hallett Dock and Tallas Island did not improve with the inclusion of the RADARSAT-2 HH polarization. Hallett Dock had a user's accuracy of $100 \%$ and a producer's accuracy of $99 \%$ for the Not Phragmites class. Only one Not Phragmites validation points was incorrectly classified as Phragmites. The total area of misclassified vegetation at Hallett Dock was $0.7 \%$ of the study area. Tallas Island followed the same trend of minimal change. The user's and producer's accuracy of the Not Phragmites class was 100\%. The total area of misclassified vegetation was $1.1 \%$ of the study site. Including the RADARSAT-2 HH polarization resulted in the lowest classification accuracy of Saginaw Bay. No Phragmites in the study area was identified correctly resulting in a producer's accuracy of $0 \%$. The user's accuracy of the Not Phragmites class was $72 \%$, and the producer's accuracy was $100 \%$. 


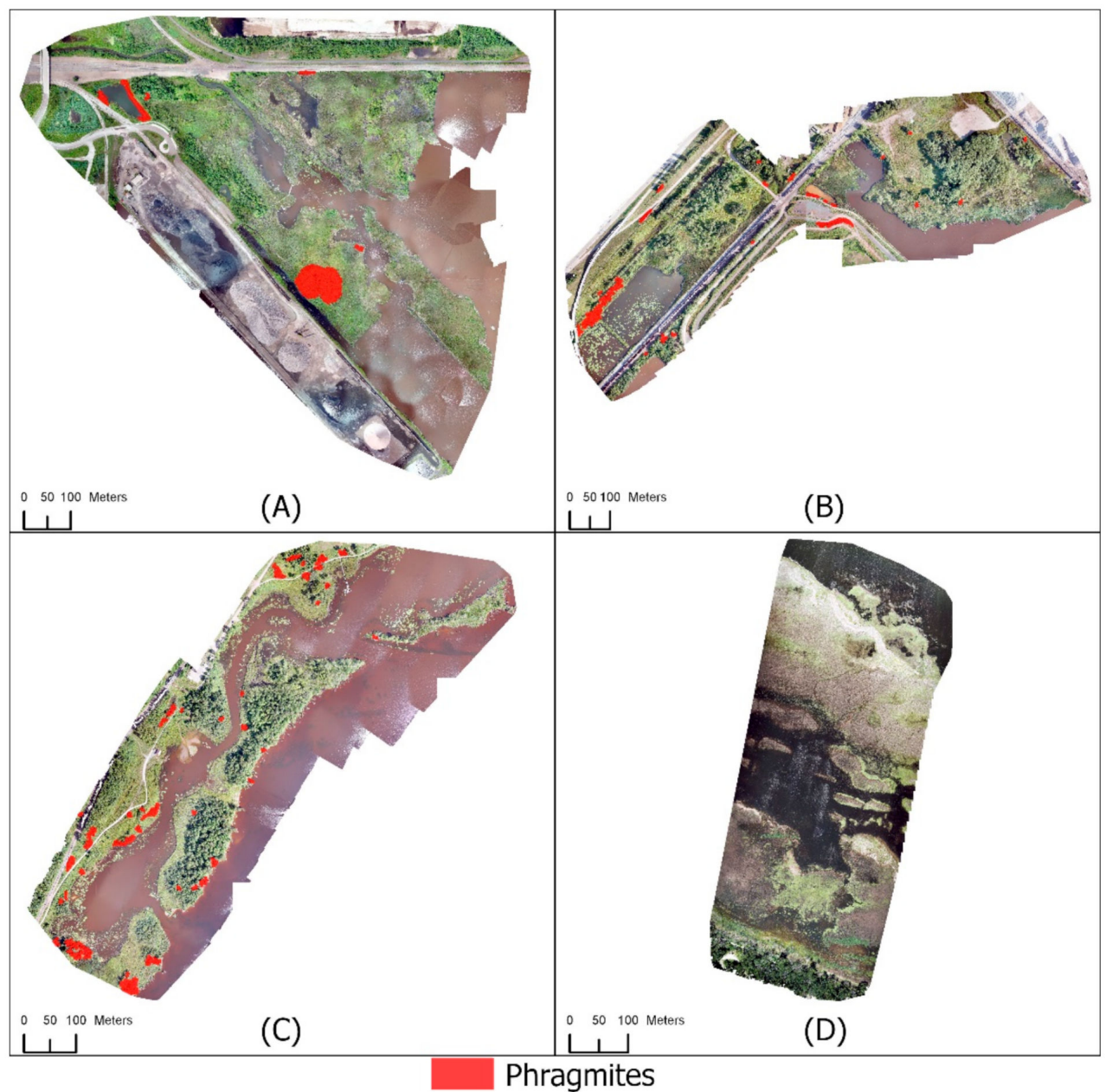

Figure 8. Mapping Phragmites using RGB UAS imagery, UAS-derived CHM, and RADARSAT-2 HH polarization for (A) Grassy Point Park, (B) Hallett Dock, (C) Tallas Island, and (D) Saginaw Bay.

Table 11. Validated assessment points from each study area for the classification using the RGB UAS imagery, a UAS-derived CHM, and RADARSAT-2 HH polarization. Points are split by class (Phragmites, Not Phragmites) and if they were correctly identified (Correct, Incorrect).

\begin{tabular}{ccccc}
\hline & \multicolumn{2}{c}{ Phragmites Class } & \multicolumn{2}{c}{ Not Phragmites Class } \\
\cline { 2 - 5 } Study Area & Correct & Incorrect & Correct & Incorrect \\
\hline Grassy Point Park & 34 & 11 & 81 & 4 \\
Hallett Dock & - & - & 127 & 1 \\
Saginaw Bay & 0 & 37 & 93 & 0 \\
Tallas Island & - & - & 130 & 0 \\
\hline
\end{tabular}


Table 12. Classification performance for all four study sites when using RGB UAS imagery, UASderived CHM, and RADARSAT-2 HH polarization. Producer's accuracy and user's accuracy are provided for each study site. Only the accuracy of the Not Phragmites class was calculated for Hallett Dock and Tallas Island. The combined accuracy of the Not Phragmites class was not calculated.

\begin{tabular}{|c|c|c|c|c|c|}
\hline \multirow[b]{2}{*}{ Class } & \multirow[b]{2}{*}{ Grassy Point } & \multicolumn{4}{|c|}{ Study Area } \\
\hline & & Hallett Dock & Tallas Island & Saginaw Bay & Combined \\
\hline \multicolumn{6}{|c|}{$\begin{array}{l}\text { Producer's Accuracy } \\
(\%)\end{array}$} \\
\hline Phragmites & 76 & $\mathrm{~N} / \mathrm{A}$ & $\mathrm{N} / \mathrm{A}$ & 0 & 41 \\
\hline Not Phragmites & 95 & 99 & 100 & 100 & $\mathrm{~N} / \mathrm{A}$ \\
\hline \multicolumn{6}{|c|}{ User's Accuracy (\%) } \\
\hline Phragmites & 90 & $\mathrm{~N} / \mathrm{A}$ & $\mathrm{N} / \mathrm{A}$ & 0 & 87 \\
\hline Not Phragmites & 88 & 100 & 100 & 72 & $\mathrm{~N} / \mathrm{A}$ \\
\hline
\end{tabular}

Overall, results from this study suggest that the inclusion of the RADARSAT-2 HH polarization does not necessarily increase the classification accuracy of Phragmites (Table 12). Five Not Phragmites validation points were incorrectly classified as Phragmites resulting in a combined user's accuracy for $87 \%$. However, the omission of Phragmites at Saginaw Bay resulted in a combined producer's accuracy of $41 \%$ for the Phragmites class.

\section{Discussion}

This study used OBIA to identify Phragmites from three-band UAS imagery and tested the functionality of CHMs and SAR within those classifications. Based on the results in four study locations, accurate identification of Phragmites from UAS imagery is unlikely without the use of a CHM. This is clearly demonstrated by the low producer's and user's accuracies of the Phragmites class when not using a CHM. Visual analysis of the resulting classifications showed that trees, shrubs, and Typha spp. were highly subject to commission errors in each of the four study sites. Phragmites in the training location exhibited rough textures due to shadowing, which corresponds to low GLCM homogeneity values. Misclassification of woody vegetation and Typha spp. may be due to their similar textural values as Phragmites.

\subsection{Use of CHMs for Phragmites Identification}

Inclusion of a CHM allowed for a significant increase $(>20 \%)$ in classification accuracy for three of the four study sites. The increased accuracy is attributed to the exclusion of wetland trees, shrubs, and shorter wetland vegetation from the final Phragmites class. It is possible that the CHM had further impacts. The CHM was used with the RGB imagery when calculating GLCM homogeneity and contrast. Texture values of objects changed, which resulted in objects being included or excluded from the final Phragmites class. Although the separation of vegetation by height resulted in the most significant change to classifications using a CHM, the texture values calculated with the addition of a CHM were important for the classification and refinement of Phragmites objects. In comparison, using texture without a CHM resulted in broad misclassification. Further research is needed to determine the role of textural algorithms for Phragmites classification.

Although the inclusion of a CHM provided a large increase in classification accuracy in three study sites, results from the Saginaw Bay study site demonstrate that classification accuracy is tied to the quality of the CHM. Each study site was flown without ground control points while using single-frequency GNSS equipment. Errors in positional estimates of the UAS will propagate through the workflow, lowering the accuracy of the subsequent UAS data. Phragmites frequently invades locations where ground control points are difficult to establish. A UAS with post-processing kinematic (PPK) or real-time kinematic (RTK) capabilities would increase positional accuracy [79-81] and decrease CHM errors. CHM accuracy is also dependent on the quality of the lidar used to create the DEM. Density of Phragmites patches may inhibit the lidar laser pulse from striking the ground or water surface below, resulting in returns being incorrectly classified (i.e., vegetation returns classified as ground returns). This issue may be circumvented where Phragmites is growing 
as emergent vegetation. A single parameter, mean water level, for example, could be used to create the CHM. However, this method would not be appropriate elsewhere. More testing is needed to determine how to achieve accurate DEMs in locations that Phragmites invades, as well as the impact of a PPK or RTK enabled UAS on classification accuracy.

The results seen at Saginaw Bay were attributed to the potential CHM errors described above. Portions of live and dead Phragmites stands can be seen in the lidar DEM. Additionally, the GNSS instruments on the DJI Mavic Pro may not be accurate enough for estimating emergent vegetation height. Visual assessment of the UAS-derived DSM showed significant underestimation of vegetation height. This was present even when accounting for potential errors in the lidar-derived DEM. For example, most vegetation was estimated to be under one meter tall. More research is needed to confirm whether a DJI Mavic Pro can accurately estimate the height of Phragmites and non-Phragmites herbaceous vegetation.

Field conditions and Phragmites patch characteristics during data acquisition are another critical aspect to CHM quality. The density of a Phragmites patch directly determines what can be captured in the CHM. The potential to capture individual stalks of Phragmites in a CHM is unlikely. This is due to the increased difficulty of point matching at the top of a Phragmites stalk because of its small size and frequent movement in wind. Higher density Phragmites patches provide more options for point matching, which will lead to a more accurate CHM. The potential issues with proper point matching can be compounded during flooded conditions due to the movement of water. Future research should prioritize methods, data, and field conditions that produce high-quality CHMs.

Satellite-derived CHMs had classification accuracies that were slightly lower than the UAS-derived CHMs. Saginaw Bay was the only study area that had a higher classification accuracy with the satellite-derived CHM than the UAS-derived CHM, but this is attributed to the accuracy of the GNSS equipment on the DJI Mavic Pro. Commission errors were more abundant at the boundaries of tree lines and low vegetation than when using a UAS-derived CHM. This is attributed to the lower spatial resolution of the satellite-derived CHMs. Larger pixel size inhibits a distinct boundary between the tree canopy and low vegetation canopy. Additionally, commission errors may be attributed to the vertical accuracy and adjustment method of the satellite-derived CHMs. Others have noted errors of multiple meters when using commercial satellite stereo retrievals to estimate canopy height [82-84]. Errors of this magnitude will directly impact the detection of Phragmites. Examples of this error can be seen in both the Hallett Dock and Tallas Island study sites. Large sections of herbaceous vegetation were correctly classified in these two sites when using a UAS-derived CHM, but the same areas were incorrectly classified when using a satellite-derived CHM. This issue highlights the need for the evaluation of DSMs created using the SETSM algorithm.

Implications of large-area Phragmites identification is promising despite the commission errors when using a satellite-derived CHM. Knowing that a CHM is necessary for accurate Phragmites identification, a major issue with large-area identification is having a CHM from the same growing season as the optical imagery. Phragmites patches can expand rapidly during a growing season [85], new patches can establish between years, and active management can reduce patch size and change patch shape. Outdated CHMs would result in inaccurate classifications, potentially causing unaccounted or incorrectly identified Phragmites patches. These errors could lead to mismanagement of resources apportioned to control Phragmites. Large-area lidar acquisitions are infrequent, and vegetation structure and abundance will change after the acquisition. Satellite-derived CHMs allow for classifications to use CHMs from the same day as the optical imagery. In addition to up-to-date CHMs, optical satellites frequently collect more than just the RBG spectral bands, which will assist in the discrimination of vegetation [86]. Large-area identification of Phragmites using satellite-derived CHMs is the subject of our ongoing studies. 


\subsection{SAR for Phragmites Identification}

Use of the RADARSAT-2 HH polarization did not improve classification accuracy at any of the four study sites. These results are similar to Millard and Richardson (2013) [87] who found no improvement when pairing SAR with lidar derivatives for wetland classification. Tallas Island and Hallett Dock had no increase in accuracy or decrease in commission errors when incorporating the $\mathrm{HH}$ polarization. Commission errors at Grassy Point were reduced to only three objects being misclassified as Phragmites. Contrarily, omission errors were significantly higher in Saginaw Bay where no Phragmites was correctly identified. This is attributed to different environmental conditions in the St. Louis River Estuary and Lake Huron. However, these environmental conditions, which are not exclusive to Saginaw Bay, could be present in wetlands in any location. Higher $\sigma^{\circ}$ values were detected in the Saginaw Bay study site compared to the other study sites. A majority of the vegetation in Saginaw Bay was flooded, while the vegetation in the Minnesota study sites was not. The $\mathrm{HH}$ polarization is more sensitive to double-bounce scattering, and flooded, tall vegetation facilitates double-bounce scattering with perpendicular water-stem surfaces [32]. Although the CHM caused most omission errors in Saginaw Bay, the failure of the classifier in Saginaw Bay when incorporating the $\mathrm{HH}$ polarization was caused by the omission of Phragmites patches due to higher HH backscatter. The differences between Grassy Point and Saginaw Bay show that environmental conditions have great influence over SAR backscatter. The dielectric properties of all scattering surfaces and the geometry of those surfaces determines the intensity and polarization of the returned signal [33]. Future work should normalize SAR variables to account for environmental differences between locations.

Results from including the $\mathrm{HH}$ polarization demonstrate that using a single polarization from a single date is not effective for differentiating Phragmites from other wetland vegetation. Different SAR methods than those used in this study may prove beneficial for Phragmites mapping. For example, others have employed multiple dates of SAR imagery when identifying Phragmites [26,88]. A multi-temporal approach may provide the ability to track changes in wetland vegetation structure across the growing season. Phragmites has more aboveground biomass than other wetland species $[89,90]$ and fast rates of growth [5]. A multi-temporal approach could differentiate Phragmites from other species due to seasonal growth characteristics. Others have used polarimetric SAR (PolSAR) to identify different wetland types [91-93]. PolSAR decompositions are suitable for differentiating surface features based on their scattering behaviors [94]. Phragmites may have unique scattering characteristics relative to other wetland vegetation due to its density of stems, large amount of aboveground biomass, and the orientation of large, overlapping leaves. Further testing is needed to determine whether other SAR methods can improve the classification accuracy of Phragmites.

\subsection{Validation}

Validation of this study was done entirely through visual interpretation of the UAS imagery. Physical mapping of the St. Louis River Estuary had been completed by the GLIFWC, and other individuals provided point data on the location of known Phragmites populations, but the randomized assessment points were not physically validated. Physical validation of each assessment point would allow for higher confidence in the accuracy of each point. Furthermore, the number of Phragmites validation points in Grassy Point Park and Saginaw Bay was low, which likely reduced the precision at which class accuracies could be calculated. The size and shape of the Phragmites patches in the two study areas was not conducive for the creation of more validation points. A higher point density could have been generated, but the generally narrow shape would result in validation points being located too closely together. This brings into question how validation should be completed for classifications where the aim is to identify a cover class that covers a very small percentage of an already small study area. For invasive species mapping, this problem is especially relevant because a land manager's goal is to identify invasive species' 
extent before it becomes too costly to manage, i.e., when populations are small. Further research is needed to determine best practices for this unique problem.

\section{Conclusions}

Species identification using remote sensing is a difficult task, but the growth characteristics of Phragmites offer an avenue for its identification. CHMs can be used to highlight the unique growth characteristics of Phragmites and differentiate it from other vegetation types. This was demonstrated when using a UAS-derived CHM with the RGB UAS imagery to achieve reasonable identification accuracy. However, improvement is still needed for remote sensing to play a major role in the detection and control of this species. Additional classification techniques and data sources should be explored.

In addition, it is important to remember that remote sensing is a field based on creating data for others to use. Maps provided for invasive species management need to be accurate. Land managers will not tolerate widespread omission of Phragmites patches or misidentification of desirable native wetland species as Phragmites. This study showed that Phragmites can be successfully identified in one wetland while simultaneously being subject to numerous commission errors in another wetland. Future work should test classifiers in multiple study areas to determine their true capability for Phragmites identification. This need will become increasingly important if remote sensing is to be a viable tool for resource specialists coordinating Phragmites management.

Author Contributions: Conceptualization, C.J.A. and J.F.K.; data curation, C.J.A. and D.H.; methodology, C.J.A., D.H., K.C.P. and J.F.K.; formal analysis, C.J.A.; validation, J.L.B.; writing-original draft preparation, C.J.A.; writing-review and editing, C.J.A., D.H., K.C.P., J.L.B. and J.F.K.; funding acquisition, J.F.K. All authors have read and agreed to the published version of the manuscript.

Funding: This work was funded by the Legislative and Citizen Commission for Minnesota Resources through Minnesota's Environment and Natural Resources Trust Fund (ENRTF) via the Minnesota Invasive Terrestrial Plant and Pest Center (MITPPC) grant number ML2018 Ch214 Art.4 Sec.2 Sub.06a E818ITP.

Acknowledgments: Data for two of the UAS acquisitions were provided by the University of Minnesota Duluth NRRI GIS Lab and the Michigan Technological Research Institute. Satellite-derived DSMs were created by the University of Minnesota Polar Geospatial Center from DigitalGlobe, Inc. imagery.

Conflicts of Interest: The authors declare no conflict of interest.

\section{References}

1. Pimentel, D.; Zuniga, R.; Morrison, D. Update on the environmental and economic costs associated with alien-invasive species in the United States. Ecol. Econ. 2005, 52, 273-288. [CrossRef]

2. Saltonstall, K.; Burdick, D.; Miller, S.; Smith, B. Native and Non-native Phragmites: Challenges in Identification, Research, and Management of the Common Reed. National Estuarine Research Reserve Technical Report Series. 2005. Available online: https:/ / coast.noaa.gov/data/docs/nerrs/Research_TechSeries_Phrag_Final_2009.pdf (accessed on 30 June 2021).

3. Michigan Department of Agriculture and Rural Development. Prohibited and Restricted Weeds. 2021. Available online: https: //www.michigan.gov/documents/mdard/Michigan_Prohibited_and_Restricted_Weeds_641413_7.pdf (accessed on 30 June 2021).

4. Minnesota Department of Agriculture. Noxious Weed List. 2021. Available online: https://www.mda.state.mn.us/sites/default/ files/docs/2021-02/2021NoxiousWeedListFactsheetV2.pdf (accessed on 30 June 2021).

5. Hocking, P.J.; Finlayson, C.M.; Chick, A.J. The biology of Australian weeds. 12. Phragmites australis (Cav.) Trin. Ex Steud. J. Aust. Inst. Agric. Sci. 1983, 49, 123-132.

6. Galatowitsch, S.M.; Anderson, N.O.; Ascher, P.D. Invasiveness in wetland plants in temperate North America. Wetlands 1999, 19, 733-755. [CrossRef]

7. Chambers, R.M.; Osgood, D.T.; Bart, D.J.; Montalato, F. Phragmites australis invasion and expansion in tidal interactions among salinity, sulfide, and hydrology. Estuaries 2003, 26, 398-406. [CrossRef]

8. Weinstein, M.P.; Balletro, J.H. Does the common reed, Phragmites australis, affect essential fish habitat. Estuaries 1999, $22,793-802$. [CrossRef]

9. Bernal, B.; Megonigal, J.P.; Mozdzer, T.J. An invasive wetland grass primes deep soil carbon pools. Glob. Chang. Biol. 2017, 23, 2104-2116. [CrossRef] [PubMed]

10. Findlay, S.E.G.; Dye, S.; Kuehn, K.A. Microbial growth and nitrogen retention in litter of phragmites australis compared to typha angustifolia, wetlands. Wetlands 2002, 22, 616-625. [CrossRef] 
11. Meyerson, L.A.; Saltonstall, K.; Windham, L.; Kiviat, E.; Findlay, S. A comparison of Phragmites australis in freshwater and brackish marsh environments in North America. Wetl. Ecol. Manag. 2000, 8, 89-103. [CrossRef]

12. Chambers, R.M.; Meyerson, L.A.; Saltonstall, K. Expansion of Phragmites australis into tidal wetlands of North America. Aquat. Bot. 1999, 64, 261-273. [CrossRef]

13. Marks, M.; Lapin, B.; Randall, J. Phragmites australis (P. communis): Threats, management, and monitoring. Source Nat. Areas J. 1994, 14, 285-294.

14. Tulbure, M.G.; Johnston, C.A. Environmental conditions promoting non-native phragmites australis expansion in great lakes coastal wetlands. Wetlands 2010, 30, 577-587. [CrossRef]

15. Center for Invasive Species and Ecosystem Health, University of Georgia. Early Detection and Distribution Mapping System. Available online: https: / / www.eddmaps.org/ (accessed on 1 September 2019).

16. Collin, A.; Ramambason, C.; Pastol, Y.; Casella, E.; Rovere, A.; Thiault, L.; Espiau, B.; Siu, G.; Lerouvreur, F.; Nakamura, N.; et al. Very high resolution mapping of coral reef state using airborne bathymetric lidar surface-intensity and drone imagery. Int. J. Remote Sens. 2018, 39, 5676-5688. [CrossRef]

17. Larson, M.D.; Milas, A.S.; Vincent, R.K.; Evans, J.E. Multi-depth suspended sediment estimation using high-resolution remotesensing UAV in Maumee River, Ohio. Int. J. Remote. Sens. 2018, 39, 5472-5489. [CrossRef]

18. Lu, B.; He, Y. Species classification using Unmanned Aerial Vehicle (UAV)-acquired high spatial resolution imagery in a heterogeneous grassland. ISPRS J. Photogramm. Remote Sens. 2017, 128, 73-85. [CrossRef]

19. Wiens, J.; Sutter, R.; Anderson, M.; Blanchard, J.; Barnett, A.; Aguilar-Amuchastegui, N.; Avery, C.; Laine, S. Selecting and conserving lands for biodiversity: The role of remote sensing. Remote Sens. Environ. 2009, 113, 1370-1381. [CrossRef]

20. Willis, K.S. Remote sensing change detection for ecological monitoring in United States protected areas. Biol. Conserv. 2015, 182, 233-242. [CrossRef]

21. Müllerová, J.; Brůna, J.; Bartaloš, T.; Dvořák, P.; Vítková, M.; Pyšek, P. Timing is important: Unmanned aircraft vs. Satellite imagery in plant invasion monitoring. Front. Plant. Sci. 2017, 8, 887. [CrossRef] [PubMed]

22. Jollineau, M.Y.; Howarth, P.J. Mapping an inland wetland complex using hyperspectral imagery. Int. J. Remote Sens. 2008, 29,3609-3631. [CrossRef]

23. Harken, J.; Sugumaran, R. Classification of Iowa wetlands using an airborne hyperspectral image: A comparison of the spectral angle mapper classifier and an object-oriented approach. Can. J. Remote Sens. 2005, 31, 167-174. [CrossRef]

24. Underwood, E.; Ustin, S.; DiPietro, D. Mapping nonnative plants using hyperspectral imagery. Remote Sens. Environ. 2003, 86, 150-161. [CrossRef]

25. Pengra, B.W.; Johnston, C.A.; Loveland, T.R. Mapping an invasive plant, Phragmites australis, in coastal wetlands using the EO-1 Hyperion hyperspectral sensor. Remote Sens. Environ. 2007, 108, 74-81. [CrossRef]

26. Bourgeau-Chavez, L.L.; Kowalski, K.P.; Carlson Mazur, M.L.; Scarbrough, K.A.; Powell, R.B.; Brooks, C.N.; Huberty, B.; Jenkins, L.K.; Banda, E.C.; Galbraith, D.M.; et al. Mapping invasive Phragmites australis in the coastal Great Lakes with ALOS PALSAR satellite imagery for decision support. J. Great Lakes Res. 2013, 39, 65-77. [CrossRef]

27. Van Beijma, S.; Comber, A.; Lamb, A. Random forest classification of salt marsh vegetation habitats using quad-polarimetric airborne SAR, elevation and optical RS data. Remote Sens. Environ. 2014, 149, 118-129. [CrossRef]

28. Henderson, F.M.; Lewis, A.J. Radar detection of wetland ecosystems: A review. Int. J. Remote Sens. 2008, 29, 5809-5835. [CrossRef]

29. Amani, M.; Salehi, B.; Mahdavi, S.; Granger, J.; Brisco, B. Wetland classification in Newfoundland and Labrador using multi-source SAR and optical data integration. GIScience Remote Sens. 2017, 54, 779-796. [CrossRef]

30. Banks, S.; White, L.; Behnamian, A.; Chen, Z.; Montpetit, B.; Brisco, B.; Pasher, J.; Duffe, J. Wetland classification with multiangle/temporal SAR using random forests. Remote Sens. 2019, 11, 670. [CrossRef]

31. White, L.; Brisco, B.; Dabboor, M.; Schmitt, A.; Pratt, A. A collection of SAR methodologies for monitoring wetlands. Remote Sens. 2015, 7, 7615-7645. [CrossRef]

32. Chen, Z.; White, L.; Banks, S.; Behnamian, A.; Montpetit, B.; Pasher, J.; Duffe, J.; Bernard, D. Characterizing marsh wetlands in the Great Lakes Basin with C-band InSAR observations. Remote Sens. Environ. 2020, 242, 1-17. [CrossRef]

33. Woodhouse, I.H. Introduction to Microwave Remote Sensing; CRC Press: Boca Raton, FL, USA, 2006.

34. Neukermans, G.; Dahdouh-Guebas, F.; Kairo, J.G.; Koedam, N. Mangrove species and stand mapping in Gazi Bay (Kenya) using quickbird satellite imagery. J. Spat. Sci. 2008, 53, 75-86. [CrossRef]

35. Everitt, J.H.; Yang, C.; Deloach, C.J. Remote sensing of giant reed with quickbird satellite imagery. J. Aquat. Plant. Manag. 2005, $43,81-85$.

36. Everitt, J.H.; Yang, C.; Fletcher, R.S.; Davis, M.R.; Drawe, D.L. Using aerial color-infrared photography and QuickBird satellite imagery for mapping wetland vegetation. Geocarto Int. 2004, 19, 15-22. [CrossRef]

37. Ghioca-Robrecht, D.M.; Johnston, C.A.; Tulbure, M.G. Assessing the use of multiseason quickbird imagery for mapping invasive species in a Lake Erie coastal marsh. Wetlands 2008, 28, 1028-1039. [CrossRef]

38. Carle, M.V.; Wang, L.; Sasser, C.E. Mapping freshwater marsh species distributions using WorldView-2 high-resolution multispectral satellite imagery. Int. J. Remote Sens. 2014, 35, 4698-4716. [CrossRef]

39. Laba, M.; Downs, R.; Smith, S.; Welsh, S.; Neider, C.; White, S.; Richmond, M.; Philpot, W.; Baveye, P. Mapping invasive wetland plants in the Hudson River National Estuarine Research Reserve using quickbird satellite imagery. Remote Sens. Environ. 2008, 112, 286-300. [CrossRef] 
40. Lantz, N.J.; Wang, J. Object-based classification of Worldview-2 imagery for mapping invasive common reed, Phragmites australis. Can. J. Remote Sens. J. 2013, 39, 328-340. [CrossRef]

41. Sankey, T.; Dickson, B.; Sesnie, S.; Wang, O.; Olsson, A.; Zachmann, L. WorldView-2 high spatial resolution improves desert invasive plant detection. Photogramm. Eng. Remote Sens. 2014, 80, 885-893. [CrossRef]

42. Peerbhay, K.; Mutanga, O.; Lottering, R.; Ismail, R. Mapping Solanum mauritianum plant invasions using WorldView-2 imagery and unsupervised random forests. Remote Sens. Environ. 2016, 182, 39-48. [CrossRef]

43. Robinson, T.P.; Wardell-Johnson, G.W.; Pracilio, G.; Brown, C.; Corner, R.; van Klinken, R.D. Testing the discrimination and detection limits of WorldView-2 imagery on a challenging invasive plant target. Int. J. Appl. Earth Obs. Geoinf. 2016, 44, 23-30. [CrossRef]

44. Müllerová, J.; Pergl, J.; Pyšek, P. Remote sensing as a tool for monitoring plant invasions: Testing the effects of data resolution and image classification approach on the detection of a model plant species Heracleum mantegazzianum (giant hogweed). Int. J. Appl. Earth Obs. Geoinf. 2013, 25, 55-65. [CrossRef]

45. Müllerová, J.; Brůna, J.; Dvořák, P.; Bartaloš, T.; Vítková, M. Does the data resolution/origin matter? Satellite, airborne and UAV imagery to tackle plant invasions. Int. Arch. Photogramm. Remote Sens. Spat. Inf. Sci. ISPRS Arch. 2016, 41, 903-908. [CrossRef]

46. Samiappan, S.; Turnage, G.; Hathcock, L.; Casagrande, L.; Stinson, P.; Moorhead, R. Using unmanned aerial vehicles for highresolution remote sensing to map invasive Phragmites australis in coastal wetlands. Int. J. Remote Sens. 2017, 38, $2199-2217$. [CrossRef]

47. Abeysinghe, T.; Milas, A.S.; Arend, K.; Hohman, B.; Reil, P.; Gregory, A.; Vázquez-Ortega, A. Mapping invasive Phragmites australis in the Old Woman Creek estuary using UAV remote sensing and machine learning classifiers. Remote Sens. 2019, 11, 1380. [CrossRef]

48. Tóth, V.R. Monitoring spatial variability and temporal dynamics of phragmites using unmanned aerial vehicles. Front. Plant Sci. 2018, 9, 9. [CrossRef]

49. Puliti, S.; Ørka, H.O.; Gobakken, T.; Næsset, E. Inventory of small forest areas using an unmanned aerial system. Remote Sens. 2015, 7, 9632-9654. [CrossRef]

50. Minnesota Department of Natural Resources. Kingsbury Bay-Grassy Point Habitat Restoration Project. 2013. Available online: http:/ / files.dnr.state.mn.us/input/environmentalreview / kingsbury/eaw.pdf (accessed on 1 September 2019).

51. Pix4D. Pix4Dmapper (Version 4.2.27). Available online: http://www.pix4d.com (accessed on 1 September 2019).

52. Isenberg, M. LAStools—Efficient LiDAR Processing Software (Version 170313, Academic). Available online: http:/ / rapidlasso. com/LAStools (accessed on 1 September 2019).

53. Lee, J.-S. Digital image enhancement and noise filtering by use of local statistics. IEEE Trans. Pattern Anal. Mach. Intell. 1980, 2, 165-168. [CrossRef] [PubMed]

54. Grings, F.; Ferrazzoli, P.; Karszenbaum, H.; Tiffenberg, J.; Kandus, P.; Guerriero, L.; Jacobo-Berrles, J.C. Modeling temporal evolution of junco marshes radar signatures. IEEE Trans. Geosci. Remote Sens. 2005, 43, 2238-2244. [CrossRef]

55. Grings, F.M.; Ferrazzoli, P.; Jacobo-Berlles, J.C.; Karszenbaum, H.; Tiffenberg, J.; Pratolongo, P.; Kandus, P. Monitoring flood condition in marshes using em models and envisat ASAR observations. IEEE Trans. Geosci. Remote Sens. 2006, 44, 936-941. [CrossRef]

56. S1TBX-ESA Sentinel-1 Toolbox (Version 6.0.7). Available online: http:/ / step.esa.int (accessed on 1 September 2019).

57. SNAP-ESA Sentinel Application Platform (Version 6.0.6). Available online: http:/ / step.esa.int (accessed on 1 September 2019).

58. Noh, M.J.; Howat, I.M. The surface extraction from TIN based search-space minimization (SETSM) algorithm. ISPRS J. Photogramm. Remote Sens. 2017, 129, 55-76. [CrossRef]

59. GDAL/OGR Contributors (2019) Contributors. GDAL/OGR Geospatial Data Abstraction Software Library 2019. Available online: https://github.com/OSGeo/gdal/blob/master/CITATION (accessed on 1 September 2019).

60. Environmental Systems Research Institute. ArcMap (Version 10.7). Available online: http://www.esri.com (accessed on 1 September 2019).

61. Chabot, D.; Dillon, C.; Shemrock, A.; Weissflog, N.; Sager, E.P.S. An object-based image analysis workflow for monitoring shallow-water aquatic vegetation in multispectral drone imagery. ISPRS Int. J. Geo-Inf. 2018, 7, 294. [CrossRef]

62. Pande-Chhetri, R.; Abd-Elrahman, A.; Liu, T.; Morton, J.; Wilhelm, V.L. Object-based classification of wetland vegetation using very high-resolution unmanned air system imagery. Eur. J. Remote Sens. 2017, 50, 564-576. [CrossRef]

63. Fu, B.; Wang, Y.; Campbell, A.; Li, Y.; Zhang, B.; Yin, S.; Xing, Z.; Jin, X. Comparison of object-based and pixel-based Random Forest algorithm for wetland vegetation mapping using high spatial resolution GF-1 and SAR data. Ecol. Indic. 2017, 73, 105-117. [CrossRef]

64. Halabisky, M.; Babcock, C.; Moskal, L.M. Harnessing the temporal dimension to improve object-based image analysis classification of wetlands. Remote Sens. 2018, 10, 1467. [CrossRef]

65. Jones, D.; Pike, S.; Thomas, M.; Murphy, D. Object-based image analysis for detection of Japanese Knotweed s.l. taxa (polygonaceae) in Wales (UK). Remote Sens. 2011, 3, 319-342. [CrossRef]

66. Dronova, I. Object-based image analysis in wetland research: A review. Remote Sens. 2015, 7, 6380-6413. [CrossRef]

67. Blaschke, T. Object based image analysis for remote sensing. ISPRS J. Photogramm. Remote Sens. 2010, 65, 2-16. [CrossRef]

68. Benz, U.C.; Hofmann, P.; Willhauck, G.; Lingenfelder, I.; Heynen, M. Multi-resolution, object-oriented fuzzy analysis of remote sensing data for GIS-ready information. ISPRS J. Photogramm. Remote Sens. 2004, 58, 239-258. [CrossRef] 
69. Witharana, C.; Civco, D.L.; Meyer, T.H. Evaluation of data fusion and image segmentation in earth observation based rapid mapping workflows. ISPRS J. Photogramm. Remote Sens. 2014, 87, 1-18. [CrossRef]

70. Trimble. eCognition Developer (Version 9.4). Available online: https://geospatial.trimble.com/products-and-solutions/ ecognition (accessed on 1 September 2019).

71. Wang, X.; Wang, M.; Wang, S.; Wu, Y. Extraction of vegetation information from visible unmanned aerial vehicle images. Trans. Chin. Soc. Agric. Eng. 2015, 31, 152-159. [CrossRef]

72. Alvarez-Taboada, F.; Paredes, C.; Julián-Pelaz, J. Mapping of the invasive species hakea sericea using unmanned aerial vehicle (UAV) and WorldView-2 imagery and an object-oriented approach. Remote Sens. 2017, 9, 913. [CrossRef]

73. Kattenborn, T.; Lopatin, J.; Förster, M.; Braun, A.C.; Fassnacht, F.E. UAV data as alternative to field sampling to map woody invasive species based on combined Sentinel-1 and Sentinel-2 data. Remote Sens. Environ. 2019, 227, 61-73. [CrossRef]

74. Bradley, B.A. Remote detection of invasive plants: A review of spectral, textural and phenological approaches. Biol. Invasions 2014, 16, 1411-1425. [CrossRef]

75. Meyer, G.E.; Mehta, T.; Kocher, M.F.; Mortensen, D.A.; Samal, A. Textural imaging and discriminant analysis for distinguishing weeds for spot spraying. Trans. Am. Soc. Agric. Eng. 1998, 41, 1189-1197. [CrossRef]

76. Haralick, R.M.; Shanmugam, K.; Dinstein, I. Textural features for image classification. IEE Trans. Syst. Man Cybern. 1973, 6, 610-621. [CrossRef]

77. Congalton, R.G. A review of assessing the accuracy of classifications of remotely sensed data. Remote Sens. Environ. 1991, 37, 35-46. [CrossRef]

78. Congalton, R.G.; Green, K. Assessing the Accuracy of Remotely Sensed Data: Principles and Practices, 3rd ed.; CRC Press: Boca Raton, FL, USA, 2019.

79. Zhang, H.; Aldana-Jague, E.; Clapuyt, F.; Wilken, F.; Vanacker, V.; Van Oost, K. Evaluating the potential of post-processing kinematic (PPK) georeferencing for UAV-based structure-from-motion (SfM) photogrammetry and surface change detection ETH Library Evaluating the potential of post-processing kinematic (PPK) georeferencing for UAV-based structure-from-motion (SfM) photogrammetry and surface change detection. Earth Surf. Dynam. 2019, 7, 807-827. [CrossRef]

80. Tomaštík, J.; Mokroš, M.; Surový, P.; Grznárová, A.; Merganič, J. UAV RTK/PPK method-An optimal solution for mapping inaccessible forested areas? Remote Sens. 2019, 11, 721. [CrossRef]

81. Fazeli, H.; Samadzadegan, F.; Dadrasjavan, F. Evaluating the potential of RTK-UAV for automatic point cloud generation in 3D rapid mapping. Int. Arch. Photogramm. Remote Sens. Spat. Inf. Sci. ISPRS Arch. 2016, 41, 221-226. [CrossRef]

82. Järnstedt, J.; Pekkarinen, A.; Tuominen, S.; Ginzler, C.; Holopainen, M.; Viitala, R. Forest variable estimation using a highresolution digital surface model. ISPRS J. Photogramm. Remote Sens. 2012, 74, 78-84. [CrossRef]

83. Yu, X.; Hyyppä, J.; Karjalainen, M.; Nurminen, K.; Karila, K.; Vastaranta, M.; Kankare, V.; Kaartinen, H.; Holopainen, M.; Honkavaara, E.; et al. Comparison of laser and stereo optical, SAR and InSAR point clouds from air- and space-borne sources in the retrieval of forest inventory attributes. Remote Sens. 2015, 7, 15933-15954. [CrossRef]

84. White, J.C.; Wulder, M.A.; Vastaranta, M.; Coops, N.C.; Pitt, D.; Woods, M. The utility of image-based point clouds for forest inventory: A comparison with airborne laser scanning. Forests 2013, 4, 518-536. [CrossRef]

85. Warren, S.R.; Fell, P.E.; Grimsby, J.L.; Buck, E.L.; Rilling, G.C.; Fertik, R.A. Rates, Patterns, and impacts of Phragmites australis expansion and effects of experimental Phragmites control on vegetation, macroinvertebrates, and fish within tidelands of the lower connecticut river. Estuaries 2001, 24, 90-107. [CrossRef]

86. Schmidt, K.S.; Skidmore, A.K. Spectral discrimination of vegetation types in a coastal wetland. Remote Sens. Environ. 2003, 85, 92-108. [CrossRef]

87. Millard, K.; Richardson, M. Wetland mapping with LiDAR derivatives, SAR polarimetric decompositions, and LiDAR-SAR fusion using a random forest classifier. Can. J. Remote Sens. 2013, 39, 290-307. [CrossRef]

88. Bourgeau-Chavez, L.L.; Riordan, K.; Powell, R.B.; Miller, N.; Nowels, M. Improving wetland characterization with multi-sensor, multi-Improving wetland characterization with multi-sensor, multi-temporal SAR and optical/infrared data fusion. In Advances in Geoscience and Remote Sensing; IntechOpen: London, UK, 2009; pp. 679-708.

89. Meyerson, L.A.; Chambers, R.M.; Vogt, K.A. The effects of Phragmites removal on nutrient pools in a freshwater tidal marsh ecosystem. Biol. Invasions 1999, 1, 129-136. [CrossRef]

90. Talley, T.S.; Levin, L.A. Modification of sediments and macrofauna by an invasive marsh plant. Biol. Invasions 2001, 3, 51-68. [CrossRef]

91. Corcoran, J.M.; Knight, J.F.; Gallant, A.L. Influence of multi-source and multi-temporal remotely sensed and ancillary data on the accuracy of random forest classification of wetlands in northern Minnesota. Remote Sens. 2013, 5, 3212-3238. [CrossRef]

92. Dabboor, M.; Banks, S.; White, L.; Brisco, B.; Behnamian, A.; Chen, Z.; Murnaghan, K. Comparison of compact and fully polarimetric SAR for multitemporal wetland monitoring. IEEE J. Sel. Top. Appl. Earth Obs. Remote Sens. 2019, 12, 1417-1430. [CrossRef]

93. Hong, S.-H.; Kim, H.-O.; Wdowinski, S.; Feliciano, E. Evaluation of polarimetric SAR decomposition for classifying wetland vegetation types. Remote Sens. 2015, 7, 8563-8585. [CrossRef]

94. Cloude, R.; Pottier, E. A review of target decomposition theorems in radar polarimetry. IEEE Trans. Geosci. Remote Sens. 1996, 34, 498-518. [CrossRef] 